\title{
Optimisation of Several Industrial and Recently Developed AJAM Naphtha Isomerization Processes Using Model Based Techniques
}

\author{
Aysar T. Jarullah ${ }^{1, a}$, Fayadh M. Abed ${ }^{2}$, Ahmed M. Ahmed ${ }^{1}$, Iqbal M. Mujtaba ${ }^{3, a}$ \\ ${ }^{1}$ Tikrit University, College of Engineering, Chemical Engineering Department \\ ${ }^{2}$ Tikrit University, College of Engineering, Mechanical Engineering Department \\ ${ }^{3}$ Chemical Engineering Division, School of Engineering, University of Bradford, Bradford \\ BD7 1DP UK \\ ${ }^{a}$ Corresponding Author. Email: $\underline{\text { A.T.Jarullah@tu.edu.iq ; I.M.Mujtaba@bradford.ac.uk }}$
}

\begin{abstract}
Increasing the yield and research octane number (RON) of naphtha isomerization process are the most important issues in industries. There are many alternative industrial naphtha isomerization processes practiced around the world. In addition, AJAM is a new naphtha isomerization process proposed by the authors recently (Ahmed et al., [1]) where the isomerization reactor model was validated using real data of Baiji North Refinery (BNR) of Iraq. In this work, first, the performance of the AJAM Process is evaluated against 8 existing industrial isomerization processes in terms of RON, yield and the cost using model based optimisation techniques. To be consistent, we have used the same isomerization reactor model in all the industrial processes we evaluated here. Secondly, energy saving opportunity in the new AJAM process is studied using pinch technology.
\end{abstract}

Key words: Izomerization Process and Technologies, Optimization, Mathematical Modeling

\section{Introduction}

Recently, increasing share of isomerizate was added to the gasoline pool as a result of the stringent environmental legislation which call for bring down utilization of aromatics and olefins in gasoline. In overall generation of car fuel in the world, perpetual tendency to the toughening of its environmental properties is noticed. Hence, the worldwide and local legislation to gasoline fuel impressively restrict the content of benzene, aromatic, olefin and sulfur compounds. Producing a clean gasoline fuel with high octane number in addition to 
increasing the market demand for gasoline car fuel using a current simple naphtha isomerization technology is proved to be a very cost effective process. Thus, the improvement of isomerization process is one of the effective methods for the solution of such problem (i.e. increasing the quality (RON) and quantity (yield)) [2].

The once through operation of zeolitic isomerization process (without any recycle or bypass) is economically efficient process and may be used with low cost to increase the RON of light naphtha, but the maximum value of RON that obtained is 80 . However, such issue can be addressed by using recycle technology, by-pass technology or with the combination of both. Use of these technologies can increase the RON of light naphtha by more than 90 making an excellent component in gasoline pool [3].

The isomerization process technologies are widely used in refining applications, where light normal paraffins isomerization process is being considered recently. The reduction of benzene and limiting the aromatic and olefinic components in gasoline cause losses of the octane number in gasoline structure pool, thus the isomerization process has gained the attention to produce high octane branched paraffin's. The isomerization reactions are reversible reactions, so it is impossible to convert all low octane straight hydrocarbons chain to high octane branched hydrocarbons chain without improving the isomerization process. An environmental way for improving the quality of gasoline is through the production of branched paraffins from the normal paraffins, which can be carried out via light naphtha isomerization process having C5-C6 paraffins with taking into accounts the stringent legislations for advanced liquid fuels processing in petroleum refineries. In isomerization process, low octane paraffins are isomerized to produce a flexible high octane, free of sulfur, benzene and olefins feed stock. Also, the production of iso-butanes by isomerization process of normal butanes is again a popular application to deliver feed for alkylation process and chemical plants [4].

\subsection{Scope of This Research}

There are many isomerization processes in the world. Although the configuration of each of them varies depending on the existence of recycle or by-pass, the isomerization reactor is at the heart of each of these alternative processes. However, note that the catalysts used in such reactors and the process operating conditions vary depending on the ultimate goal. In this work, we evaluate the performance (RON, Yield and Cost) of all these configurations using model based optimisation techniques. For the reactor model in each of these industrial processes, we use our recently developed model [1]) which was validated using the 
industrial data of Baiji North Refinery (BNR) of Iraq. The performances of all these alternative configurations are then compared with the performance of our recently developed configuration [1]. Finally, we look at the energy saving opportunity of the AJAM process using the Pinch Technology.

\subsection{Novelty of this work}

In our recent study [1], a detailed process model was developed for an existing naphtha isomerization reactor of Baiji North Refinery (BNR) of Iraq which involved estimation of the kinetic parameters of the reactor. The optimal values of these kinetic parameters were estimated based on BNR data and model based optimisation technique. A new isomerization process (named as AJAM process) was then proposed in Ahmed et al., [1] using the reactor model developed. The main focus of this current paper is to evaluate the AJAM process against many other alternative industrial isomerization process technologies that have not been studied in [1] except the fact that comparison was only made between the AJAM process and the once through process. However, here, the industrial technologies such as hexorb, TIP, Ipsorb, DIH \& DIP and DIH processes are used for the purpose of evaluating the AJAM process in terms RON and checking whether one of these industrial technologies can give higher RON or not. Also the productivity of the AJAM process in addition to the overall annual cost are compared with those obtained using these industrial technologies. Finally, opportunity for reducing the energy consumption and maximizing the heat recovery for the AJAM process is also investigated in this study by using the pinch technology. The modelling, simulation and optimization processes of isomerization operations for all case studies in this work are carried out using gPROMS (general Process Modelling System) software.

\section{Alternative Isomerization Process Technologies}

To achieve higher octane number several alternative isomerization process technologies have been developed over the years in which lower octane components are separated and recycled back into the reactors. Low RON components such as normal paraffin's are separated from the isomerizate and returned to the reactor feed. Many technologies such as distillation process and molecular sieve adsorption process or combination of them are used to separate normal paraffin's. Choice of the separation techniques is an important issue that mainly depends on the feed composition, desired RON and investment cost [3]. These alternative technologies are presented and described below: 


\subsection{Once Through (OT) Process}

The once through process of Baiji isomerization unit is accomplished by Axens Company. This process is presented in Figure 1. The details of this process can be found in [1].

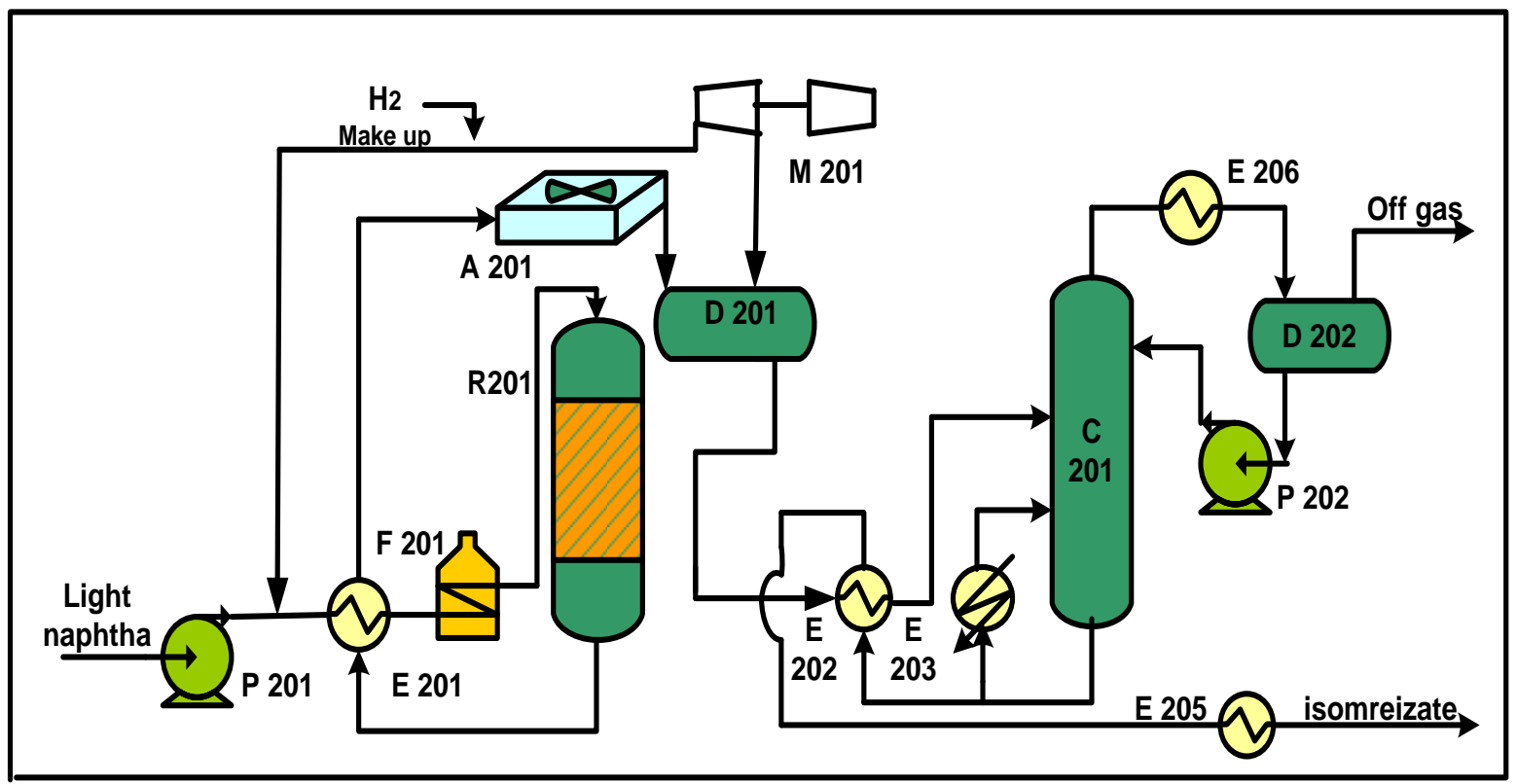

(A)

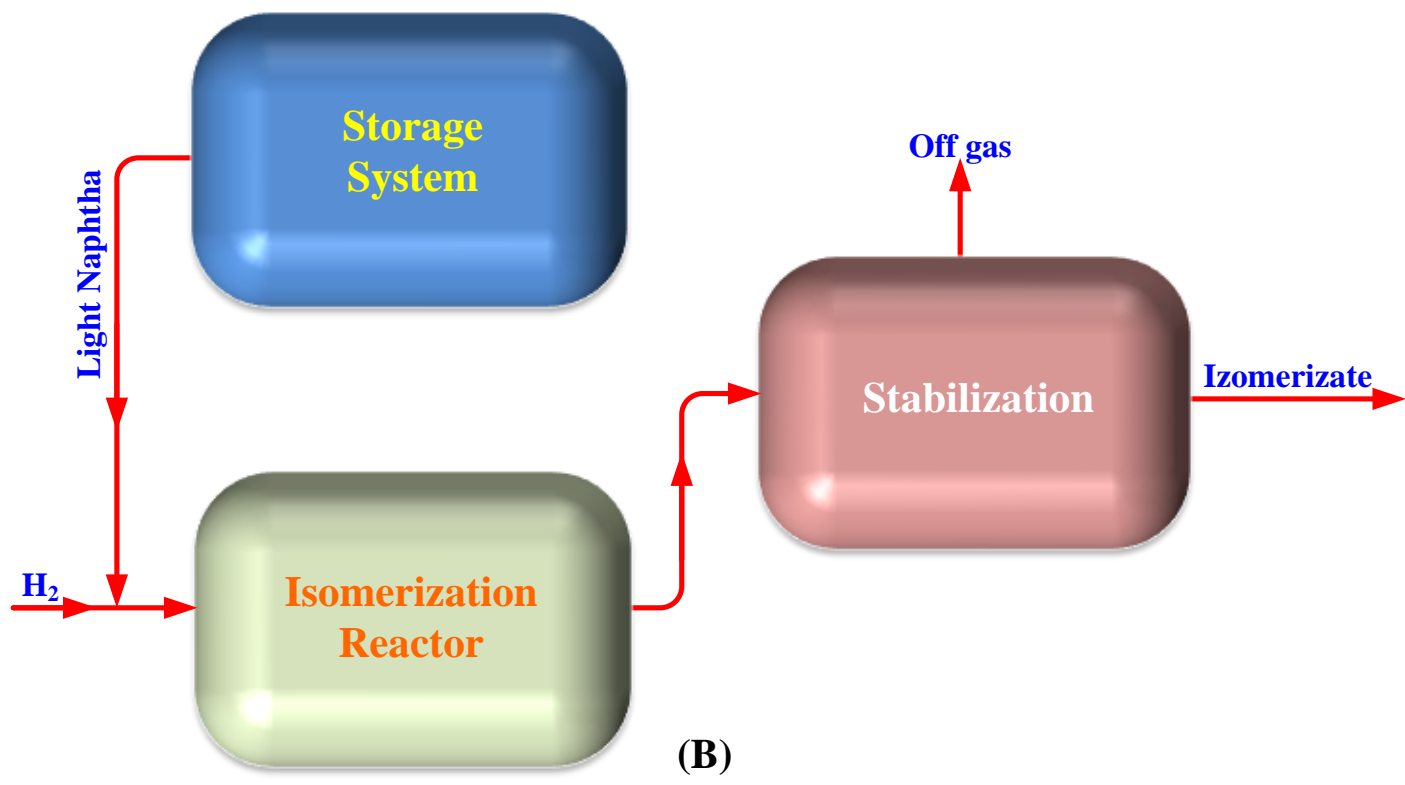

Figure 1: (A) Flow diagram of once through process (BNR) (B) Block diagram of OT process (BNR process) 


\subsection{Deisopentanizer (DIP) Process}

In this isomerization scheme shown in Figure 2, distillation column is located before the reactor to separate Iso-pentane component from light naphtha feed to increase the normal pentane conversion. The downstream of the distillation enters to the isomerization process and such process was modified by adding stabilization process for the purpose of producing stabilized isomerizate and mixing with iso-pentane stream. This scheme becomes reasonable for the composition of iso-pentane in the feed with more than $13-15 \%[2,3]$.

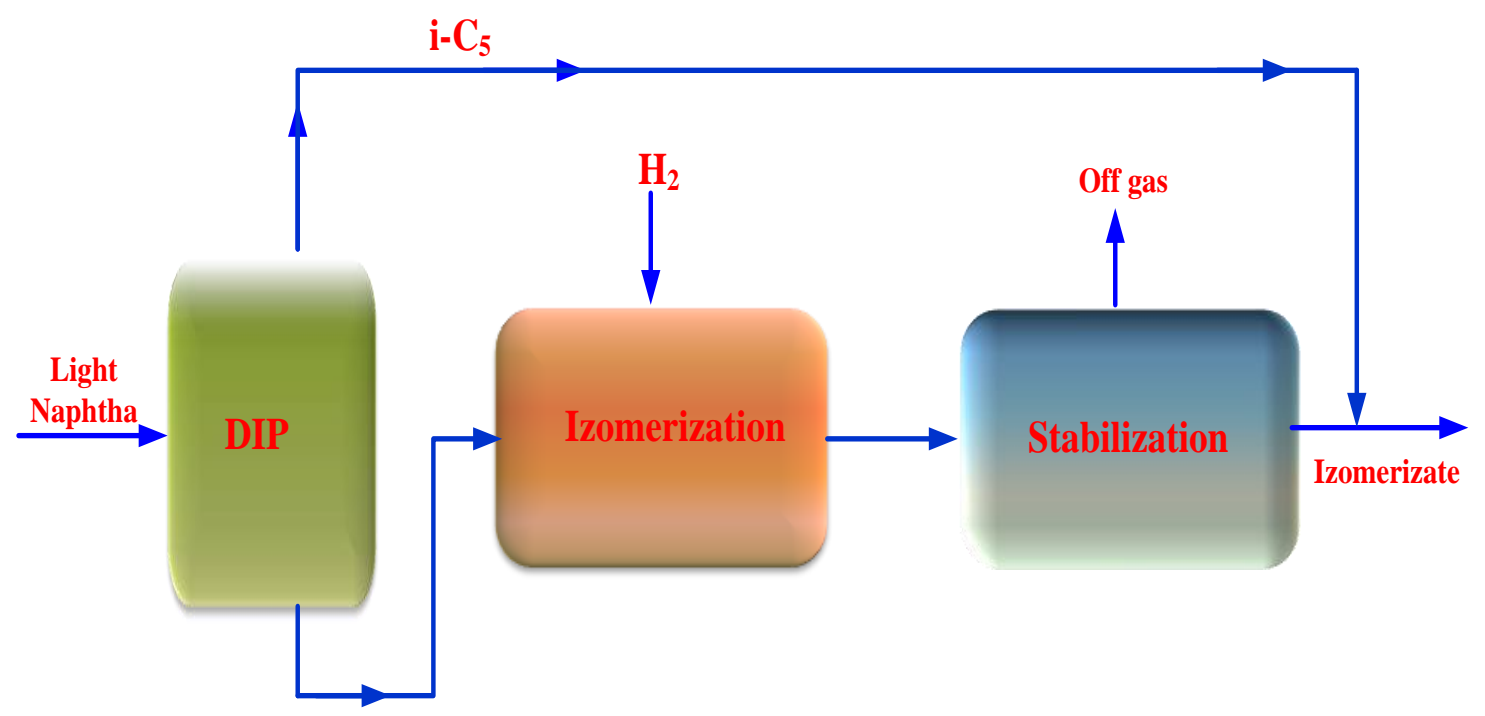

Figure 2: Block diagram of process with DIP

\subsection{Deisohexanizer (DIH) Process}

To increase the conversion of 2,2-Dimethyl butane $(\mathrm{RON}=94)$ and 2,3-Dimethyl butane $(\mathrm{RON}=105)$, normal hexane $(\mathrm{RON}=25)$, 2-methyl pentane $(\mathrm{RON}=74.4)$ and 3-methyl pentane $(\mathrm{RON}=75.5)$ are separated and recycled to the reactor. As shown in Figure 3, distillation column is used for separation process and $65 \%$ of the $\mathrm{C}_{6}$-hydrocarbons are separated from product of isomerization unit stream and recycled to the reactor inlet stream. The column is located after stabilization process and the top product of distillation is stabilized the isomerizate $[2,5]$.

\section{$2.4 \underline{\text { DIP - DIH Process }}$}

Using of DIP technology increases the conversion of normal pentane and there is no effect on the hexane conversion has observed. Also, the use of DIH increases the hexane conversion only. So, a combination between DIP and DIH is used to get high RON and yield 
as shown in Figure 4. Tow distillation columns are used, the first one is located before the isomerization unit and working as DIP (explained in case 2). The second column is located after the isomerization unit and working as DIH (explained in case 3) [2, 5].

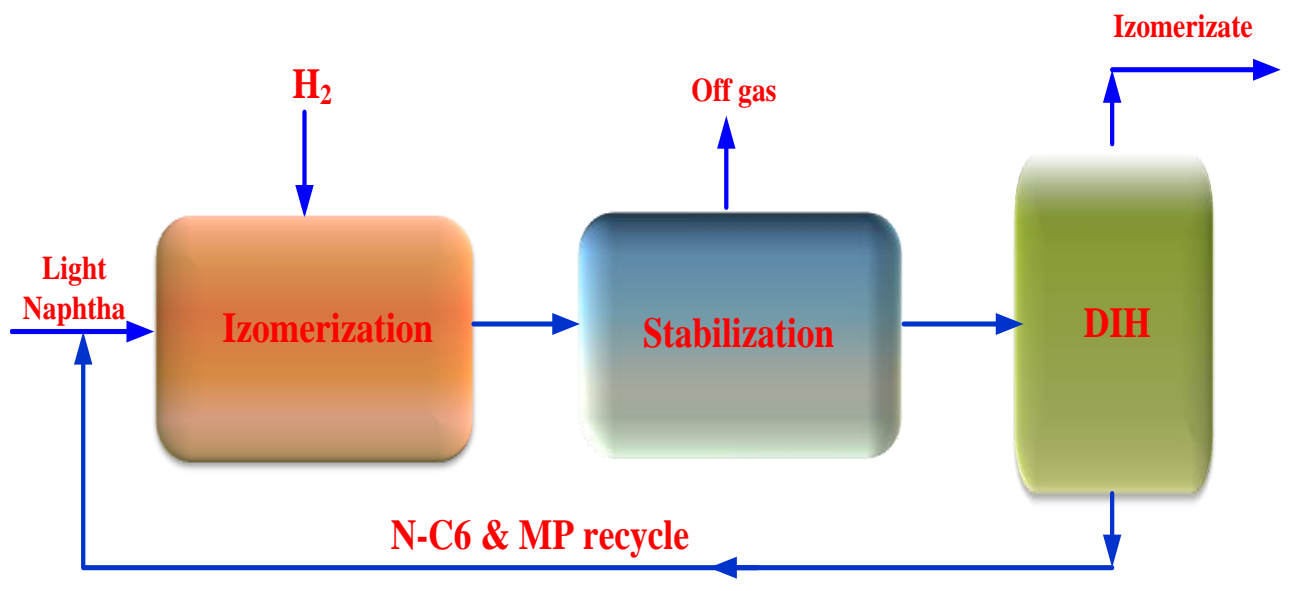

Figure 3: Block diagram of isomerization unit with DIH

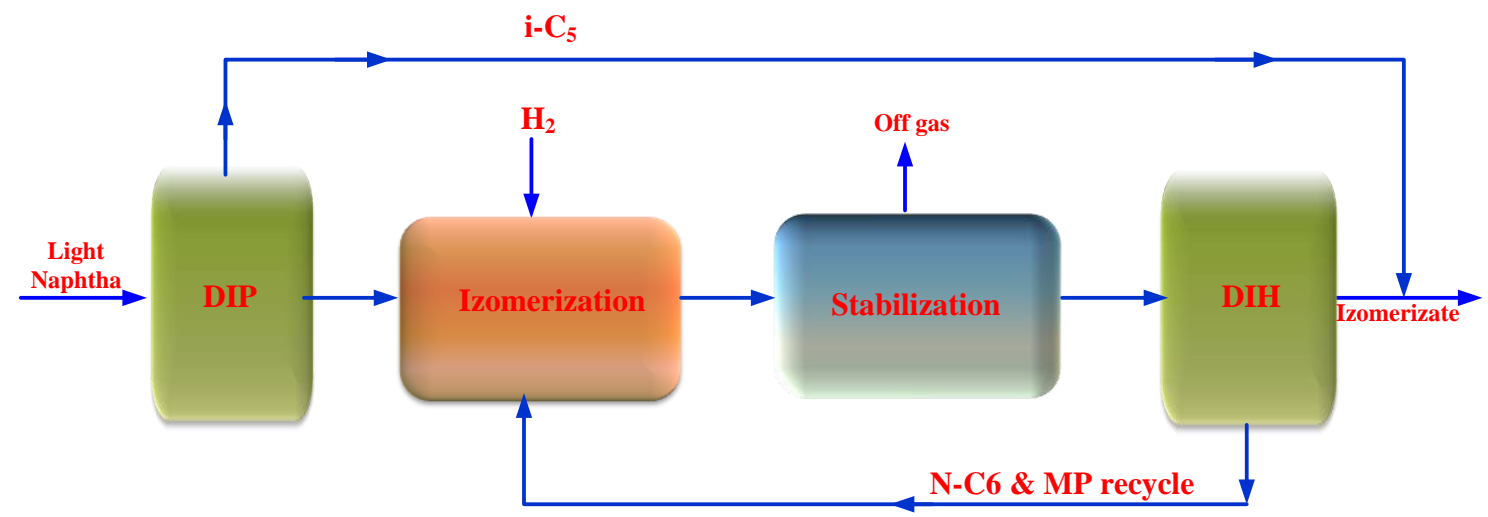

Figure 4: Block diagram of isomerization unit with DIH and DIP

\subsection{Ipsorb Process}

In this case (Figure 5), the adsorption of normal paraffin's (pentane and hexane) is used by molecular sieve adsorbers, followed by desorption from the pores and then they are recycled to the feed stock and the stream of iso-pentane is used to recover normal paraffins. This technology is developed by Axens and Zeolite $5 \mathrm{~A}$ is used as a molecular sieve. Two adsorber columns, work alternately, are located after isomerization reactor system. Adsorption process acquires the same temperature and pressure of the reactor exit stream [3, 6]. 


\subsection{Hexorb Process}

In the case 6, as shown in Figure 6, the scheme combines between the molecular sieve and DIH technology, also in the Hexorb process all normal paraffins adsorb and convert to isomers. Here, methyl pentanes (RON 74.4 and 75.5) are recycled with normal paraffins due to add DIH after molecular sieve system. After isomerization process, reactor outlet stream enters into the adsorber column to separate normal paraffins. Branched paraffins pass through adsorber bed and enter to DIH to separate methyl pentane components that are recycled to the reactor. Before entering the reactor, stream of methyl pentane is used to recover the normal paraffins from adsorber bed and recycle to the reactor $[4,5]$.

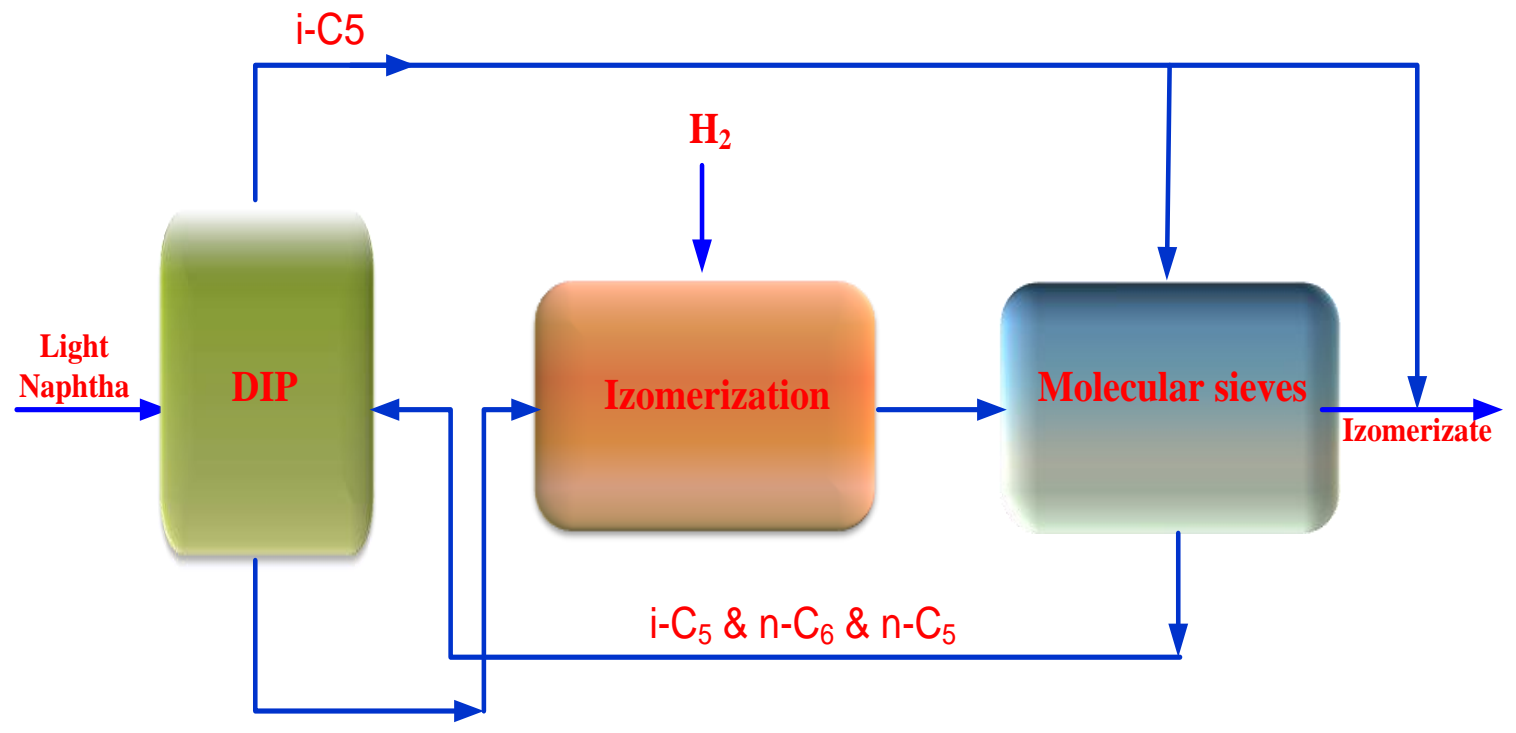

Figure 5: Block diagram of Ipsorb isomerization unit

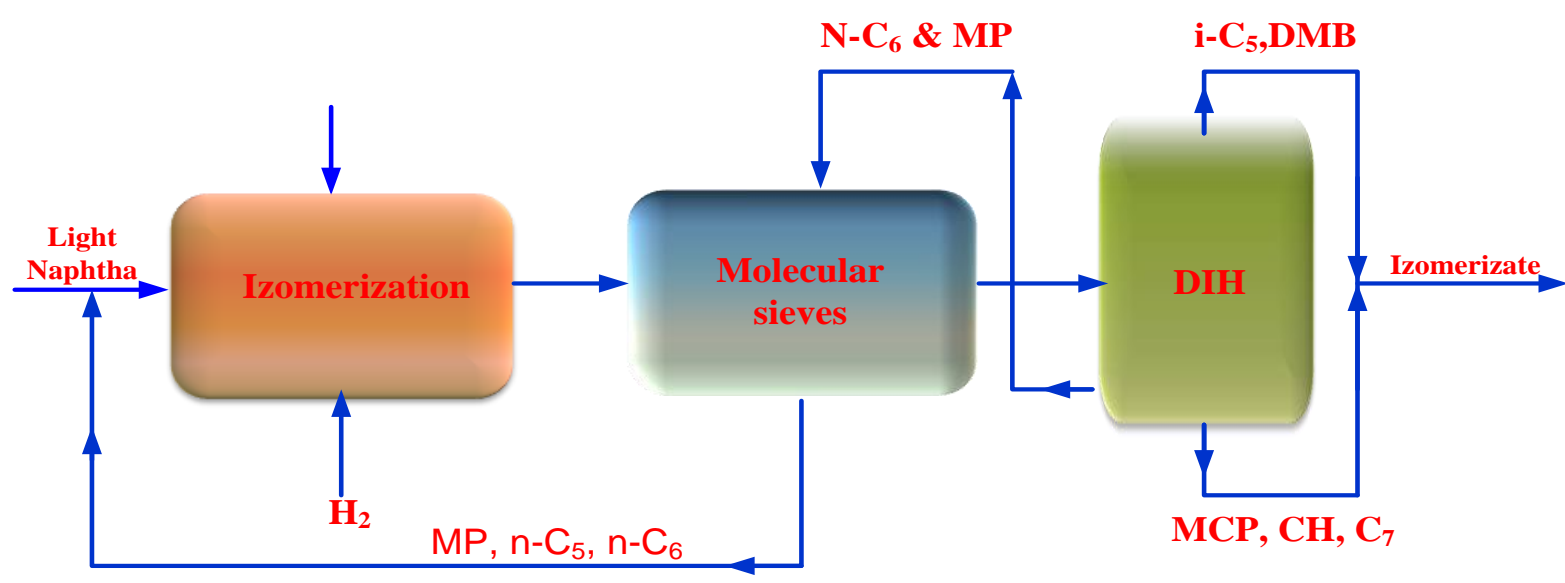

Figure 6: Block diagram of Hexorb isomerization unit 


\subsection{Total Isomerization Process (TIP)}

UOP offers the isomerization process with molecular sieves adsorption system to separate and recycling the normal paraffins. In this scheme (Figure 7), after heating light naphtha stream, the stream is entered to the isomerization reactor. The product of the reactor is entered to the adsorption towers to separate the normal paraffins and recycle it to the reactor. The stream of hydrogen is used to recover the normal paraffins from adsorber column [7].

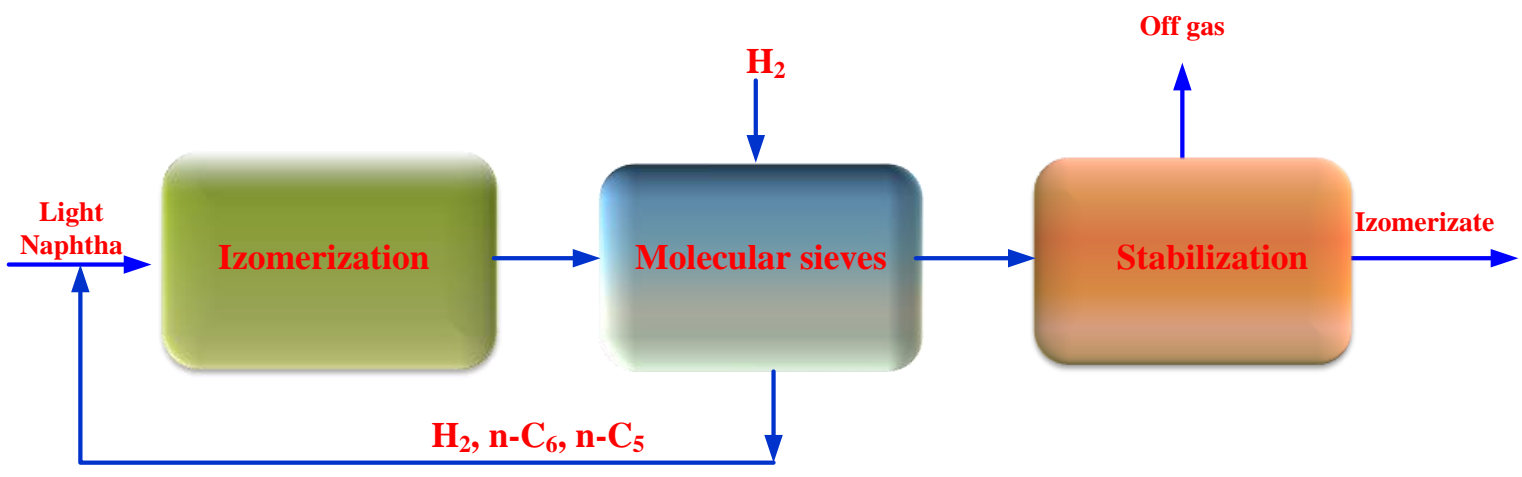

Figure 7: Block diagram of TIP isomerization unit

\subsection{AJAM Process}

Ahmed et al. [1] recently proposed this process as shown in Figure 8. They evaluated its performance against the OT process (Figure 1) for the Bajii North Refinery (BNR).

The high economic cost of molecular sieve technologies due to their high recycle rate leads to make a suitable modification on schemes of these technologies under reducing the economic cost with the same performance and to maximize RON. According to the specifications of naphtha feed stock at Baiji isomerization unit, the separation process can firstly be made owning to the content of benzene component. The new isomerization process proposed here is applied on the scheme of TIP as shown in Figure 8a,b. As firstly seems in this figure, the light naphtha stream is heated through heat exchanger (E201) and mixed with the reactor product stream and will be heated through the furnace F201befor entering to the adsorber S201. There are two adsorber columns work alternately. Through the adsorber S201, the normal paraffins are adsorbed by the molecular sieve and only branched paraffins leave the column. The normal paraffins remaining within adsorber S202 are desorbed by hydrogen stream (which is heated through the furnace F202 after compressed by Co201). The bottom stream of the adsorber S202 is entered to the reactor R201. The reactor product stream is condensed through E206 to separate the hydrogen from isomerizate stream within separator drum D201. Top product (hydrogen stream) of D201 is entered to Co201and the 
bottom product (isomerizate) is heated through E206 before mixing with light naphtha stream. The top stream of S201 is condensed through E201 and then entered to stabilization zone. After that, branched paraffins are partially vaporized through E202 by heat exchange with the bottom product of the stabilizer. Light hydrocarbons (methane, ethane, propane and part of butane) are separated from the isomerizate as a top product. The bottom product of the stabilizer (isomerizate) cooled through E202 and E204 before the storage.

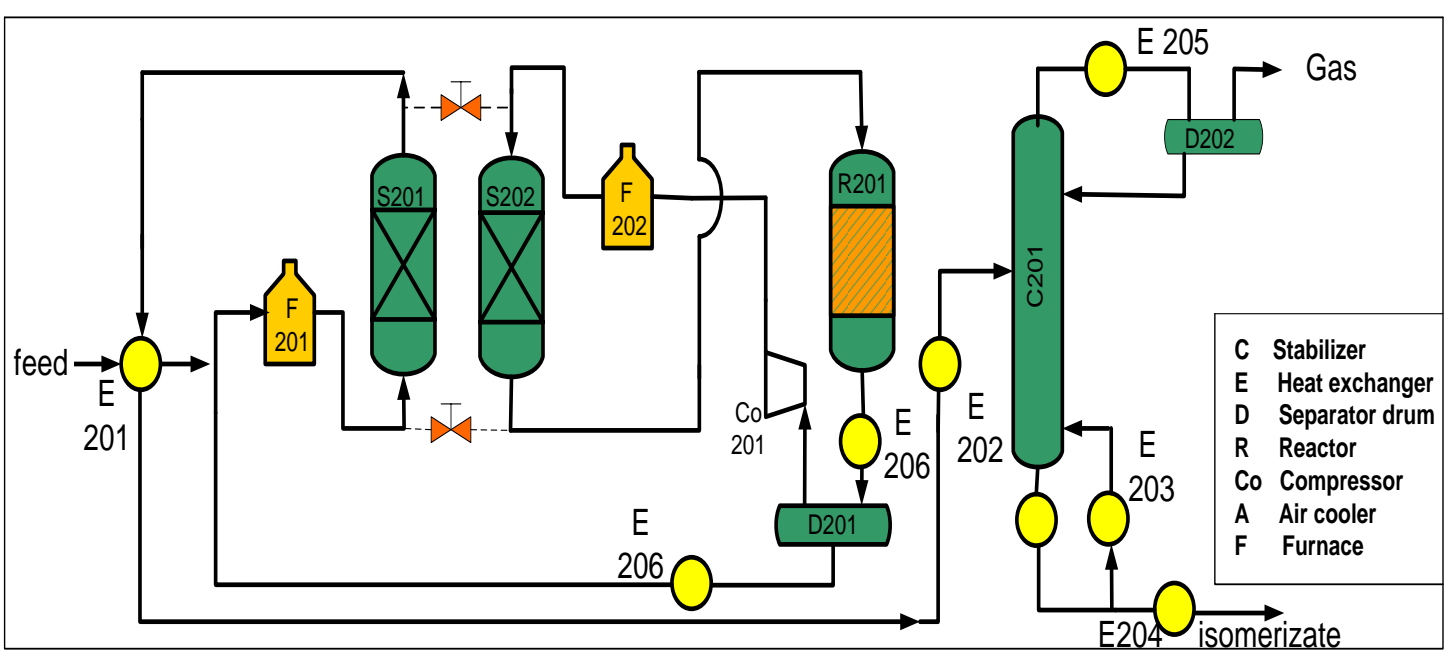

(A)

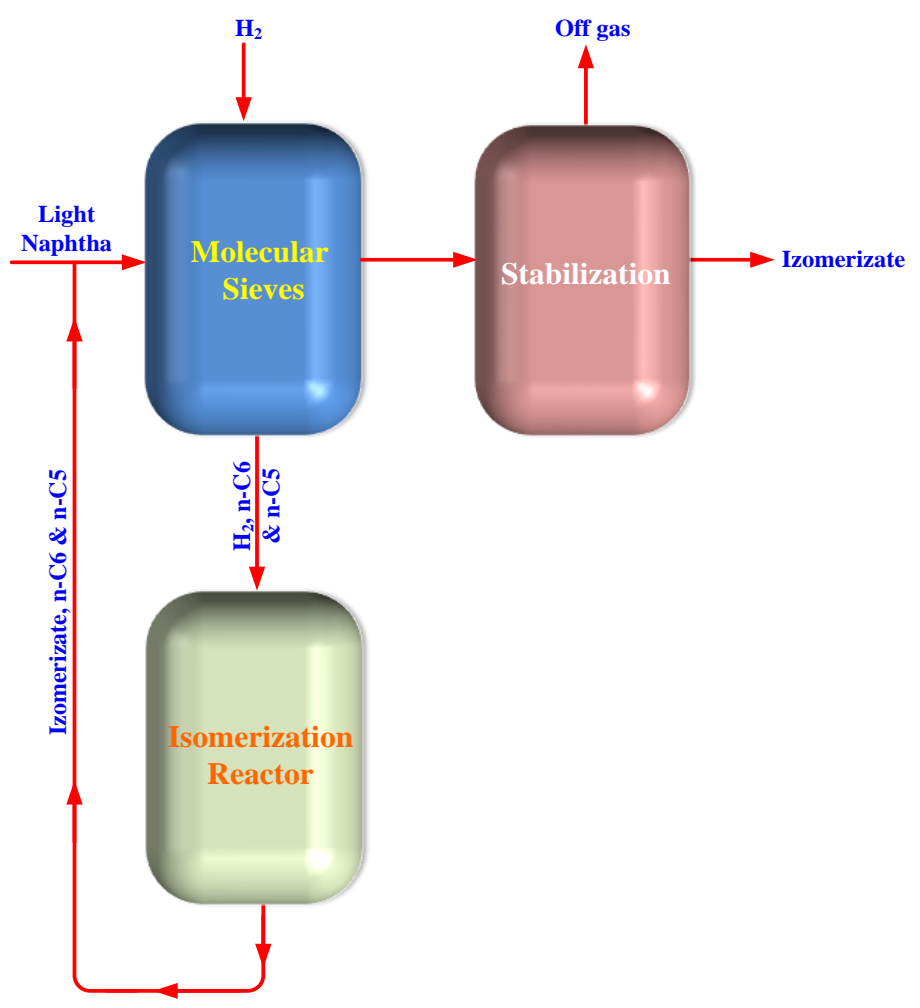

(B)

Figure 8 (A): Flow diagram of the AJAM isomerization process [1] (B): Block diagram of the AJAM isomerization process [1] 
The recycle modes of operation can lead to product octane as high as $93 \mathrm{RON}$ as shown in Table 1 [1]. Note, BNR uses Pt/Zeolite catalyst in their Once Through process. Table 2 below provides the review of the industrial isomerization processes and their performance (RON) with a brief description of operating condition, catalyst, and performance of isomerization unit at some refineries $[4,8]$.

Table 1: The RON of the isomerization process obtained by different technologies and

\begin{tabular}{lccc}
\multicolumn{4}{c}{ catalysts [2] } \\
\hline Technology & Pt/Zeolite & $\mathbf{P t}_{\mathbf{A}} \mathbf{A l}_{\mathbf{2}} \mathbf{O}_{\mathbf{3}}$ & $\mathbf{P t} / \mathbf{Z r O}_{\mathbf{2}}-\mathbf{S O}_{\mathbf{4}}$ \\
\hline Once Through (OT) & $78-80$ & 83 & $81-83$ \\
\hline DIP & 82 & 84 & $82-84$ \\
\hline DIH & 86 & 88 & $86-87$ \\
\hline DIP and DIH & - & $90-93$ & $89-90$ \\
\hline DIP, DIH and DP & - & - & $91-92$ \\
\hline TIP & $87-90$ & - & $91-92$ \\
\hline Ipsorb & 88 & 90 & - \\
\hline Hexorb & 90 & 93 & - \\
\hline $\begin{array}{l}\text { AJAM (Ahmed } \\
\text { al., 2018 }[1])\end{array}$ & $\mathbf{9 0 . 7 2}$ & - & - \\
\hline
\end{tabular}

Table 2: Operating conditions and performance of different industrial isomerization

\begin{tabular}{|c|c|c|c|c|c|}
\hline Refinery & Technology & Catalyst & $\begin{array}{l}\text { Operating } \\
\text { Conditions }\end{array}$ & $\begin{array}{l}\text { RON of } \\
\text { Isomerizate }\end{array}$ & $\begin{array}{l}\text { The } \\
\text { Licensing } \\
\text { Company }\end{array}$ \\
\hline $\begin{array}{l}\text { LUKOIL- } \\
\text { Nizhegorodne- } \\
\text { fteorgsintez }\end{array}$ & DIP & $\begin{array}{l}\text { Sulfated } \\
\text { zirconia }\end{array}$ & $\begin{array}{l}\mathrm{T}=160^{\circ} \mathrm{C} \\
\mathrm{P}=3.2 \mathrm{MPa} \\
\mathrm{LHSV}=2.5 \mathrm{hr}^{-1}\end{array}$ & $86-87$ & UOP \\
\hline Komsomolsky & DIP & $\mathrm{Pt} / \mathrm{Cl} \mathrm{Al}{ }_{2} \mathrm{O}_{3}$ & $\begin{array}{l}\mathrm{T}=130^{\circ} \mathrm{C}, \\
\mathrm{P}=3 \mathrm{MPa} \\
\text { LHSV }=2 \mathrm{hr}^{-1}\end{array}$ & 86-88 & Axens \\
\hline Achinsky & DIH & $\mathrm{Pt} / \mathrm{Cl} \mathrm{Al}{ }_{2} \mathrm{O}_{3}$ & $\begin{array}{l}\mathrm{T}=132^{\circ} \mathrm{C} \\
\mathrm{P}=2.9 \mathrm{MPa}\end{array}$ & $86-87$ & UOP \\
\hline $\begin{array}{l}\text { LUKOLL } \\
\text { Volgogradnefte- } \\
\text { pererabotka }\end{array}$ & DIP and DIH & $\mathrm{Pt} / \mathrm{Cl} \mathrm{Al}{ }_{2} \mathrm{O}_{3}$ & - & $89-90$ & UOP \\
\hline Saratovsky & $\begin{array}{l}\text { DIP, DIH and } \\
\text { DP }\end{array}$ & Pt/zeolite & - & $91-92$ & SIE \\
\hline $\begin{array}{l}\text { Orsknefteor- } \\
\text { Gsintez }\end{array}$ & Once-through & $\mathrm{Pt} /$ zeolite & - & $80-82$ & SIE \\
\hline Syzransky & DIP and DIH & Pt/zeolite & $\begin{array}{l}\mathrm{T}=240^{\circ} \mathrm{C} \\
\mathrm{P}=2.7 \mathrm{MPa} \\
\mathrm{LHSV}=3 \mathrm{hr}^{-1}\end{array}$ & $89-90$ & Axens \\
\hline Bajii & OT & $\mathrm{Pt} /$ zeolite & $\begin{array}{l}\mathrm{T}=250^{\circ} \mathrm{C} \\
\mathrm{P}=2.4 \mathrm{MPa} \\
\mathrm{LHSV}=1.6 \mathrm{hr}^{-1}\end{array}$ & $78-80$ & Axens \\
\hline- & AJAM & Pt/zeolite & $\begin{array}{l}\mathrm{T}=2488^{\circ} \mathrm{C} \\
\mathrm{P}=2.1 \mathrm{MPa} \\
\mathrm{LHSV}=1.5 \mathrm{hr}^{-1}\end{array}$ & 90.81 & - \\
\hline
\end{tabular}




\section{Isomerization Reactor Model for BNR (OT Process)}

Ahmed et al. [1] described the development of the isomerization reactor model based on real industrial data of BNR in detail. For the convenience of the reader it is summarized here. Isomerization unit of BNR is an once through mode based on zeolitic catalyst system. As shown in Figure 1a,b, light naphtha obtained by hydrotreating process is mixed with compressed hydrogen before entering heat exchanger one (E-201), which rises the temperature of the feed to $190^{\circ} \mathrm{C}$.

The furnace F-201 provides the proper level of temperature to the reactor R-201 inlet. The isomerisation chemical reactions take place into the reactor R-201 (as cylindrical with a height of $13.840 \mathrm{~m}$ and diameter of $2.9 \mathrm{~m}$ ) loaded with a bed of catalyst IP 632. The reactor effluent is partially condensed through E-201, the air condenser A-201 and the trim cooler E-202 before feeding it to the high pressure separator drum D-201 and the overhead stream (which is hydrogen) is compressed and recycled to the reactor. The liquid taken from drum D-202 is heated through heat exchanger E-202 to provide the required inlet column temperature of C-201. The head stream is partially condensed by heat exchanger E-204 then enters into the separator D-202. The downstream of C-201 is cooled through E-202 and then by E-205 to produce stabilized isomerizate.

\section{Optimization of Industrial Processes}

Here, we carry out process optimization of all the industrial processes presented in section 2 . Note, in each of these technologies, the isomerization reactor model is same as that of BNR process developed and validated recently by Ahmed et al [1]. Thus, the catalyst used for the reactor is also same (Table 2 shows 4 out 8 industrial processes use this catalyst). It is for making a fair comparison of performances between them.

\subsection{Mathematical Model}

The mathematical model used is presented in appendix A and can also be found in [1].

\subsection{Energy Balance}

Energy balance on heat transfer equipment is essential to estimate the area of heat transfer $\left(A_{t}\right)$ and heat duty $\left(Q_{F}\right)$ as a function of temperatures. The stream temperatures of once through, DIP, DIH, Ipsorb and Hexorb configurations are the same with those used in the isomerization unit at Baiji refinery (presented in Table 3). But, for TIP and the AJAM processes, the streams temperatures (presented in Table 4) were taken from Holcombe [7]. 
Heat capacities of liquid naphtha were taken from Gary at el [9], heat transfer coefficient was taken from Douglas [10]. All these parameters are presented in Tables 3 and 4.

Table 3: Values of coefficients and constant parameters used in one through, DIP, DIH, Ipsorb and Hexorb configurations

\begin{tabular}{cccccc}
\hline Parameter & Unit & Value & Parameter & Unit & Value \\
\hline $\boldsymbol{T} \mathbf{1}_{\boldsymbol{o}, \boldsymbol{h}}, \boldsymbol{T} \mathbf{2}_{\boldsymbol{o}, \boldsymbol{h}}$ & $\mathrm{K}$ & 60 & $U_{2}$ & $\mathrm{~kW} / \mathrm{m}^{2}$ & 0.387 \\
\hline $\boldsymbol{T} \mathbf{1}_{\boldsymbol{i}, \boldsymbol{c}}$ & $\mathrm{K}$ & 43 & $U_{3}$ & $\mathrm{~kW} / \mathrm{m}^{2}$ & 0.942 \\
\hline $\boldsymbol{T} \mathbf{2}_{\boldsymbol{i}, \boldsymbol{c}}, \boldsymbol{T} \mathbf{4}_{\boldsymbol{o}, \boldsymbol{c}}$ & $\mathrm{K}$ & 40 & $U_{4}, U_{5}$ & $\mathrm{~kW} / \mathrm{m}^{2}$ & 0.4 \\
\hline $\boldsymbol{T} \mathbf{2}_{\boldsymbol{i}, \boldsymbol{h}}$ & $\mathrm{K}$ & 169 & $\lambda_{c 1}$ & $\mathrm{~kJ} / \mathrm{kg}$ & 274 \\
\hline $\boldsymbol{T} \mathbf{2}_{\boldsymbol{o}, \boldsymbol{c}}$ & $\mathrm{K}$ & 132 & $\chi_{h 1}$ & $\mathrm{~kJ} / \mathrm{kg}$ & 268 \\
\hline $\boldsymbol{T 3 _ { \boldsymbol { h } }}$ & $\mathrm{K}$ & 200 & $\chi_{c 2}$ & $\mathrm{~kJ} / \mathrm{kg}$ & 317 \\
\hline $\boldsymbol{T} \mathbf{4}_{\boldsymbol{o}, \boldsymbol{h}}$ & $\mathrm{K}$ & 20 & $C p_{h 1, l}$ & $\mathrm{~kJ} / \mathrm{kg} . \mathrm{k}$ & 2.531 \\
\hline $\boldsymbol{T 4 _ { i , \boldsymbol { c } }}$ & $\mathrm{K}$ & 16 & $C p_{c 1, l}$ & $\mathrm{~kJ} / \mathrm{kg} . \mathrm{k}$ & 2.522 \\
\hline $\boldsymbol{T} \mathbf{1}_{\boldsymbol{b}, \boldsymbol{h}}, \boldsymbol{T} \mathbf{1}_{\boldsymbol{b}, \boldsymbol{c}}$ & $\mathrm{K}$ & 450 & $C p_{c 2, l}$ & $\mathrm{~kJ} / \mathrm{kg} . \mathrm{k}$ & 2.481 \\
\hline $\boldsymbol{T} \mathbf{2}_{\boldsymbol{b}, \boldsymbol{c}}$ & $\mathrm{K}$ & 386 & $C p_{l, 4}$ & $\mathrm{~kJ} / \mathrm{kg} . \mathrm{k}$ & 2.388 \\
\hline $\boldsymbol{U}_{\mathbf{1}}$ & $\mathrm{kW} / \mathrm{m}^{2}$ & 0.432 & $C p_{l, 5}$ & $\mathrm{~kJ} / \mathrm{kg} . \mathrm{k}$ & 2.388 \\
\hline
\end{tabular}

Table 4: Values of streams temperatures, coefficients and constant parameters used in TIP and ACP configurations

\begin{tabular}{|c|c|c|c|c|c|}
\hline Parameter & Unit & Value & Parameter & Unit & Value \\
\hline$T 1_{o, h}, T 2_{o, h}, T 3_{o, h}$ & $\mathrm{~K}$ & 333 & $U_{2}$ & $\mathrm{~kW} / \mathrm{m}^{2}$ & 0.432 \\
\hline$T 1_{i, c}, T 2_{i, c}, T 3_{i, c}$ & $\mathrm{~K}$ & 313 & $U_{3}$ & $\mathrm{~kW} / \mathrm{m}^{2}$ & 0.387 \\
\hline$T 1_{o, c}$ & $\mathrm{~K}$ & 505 & $U_{4}$ & $\mathrm{~kW} / m^{2}$ & 0.913 \\
\hline$T 2_{o, c}$ & $\mathrm{~K}$ & 537 & $U_{5}, U_{6}$ & $\mathrm{~kW} / m^{2}$ & 0.4 \\
\hline$T 3_{i, h}$ & $\mathrm{~K}$ & 442 & $\lambda_{c 1}$ & $\mathrm{~kJ} / \mathrm{kg}$ & 274 \\
\hline$T 3_{o, c}$ & $\mathrm{~K}$ & 405 & $\lambda_{h 1}$ & $\mathrm{~kJ} / \mathrm{kg}$ & 268 \\
\hline$T 4_{i, h}, T 4_{o, h}$ & $\mathrm{~K}$ & 463 & $\lambda_{c 2}$ & $\mathrm{~kJ} / \mathrm{kg}$ & 317 \\
\hline$T 5_{i, c}, T 6_{i, c}$ & $\mathrm{~K}$ & 288 & $C p_{h 1, l}$ & kJ/kg.k & 2.531 \\
\hline$T 5_{o, c}, T 6_{o, c}$ & $\mathrm{~K}$ & 313 & $C p_{c 1, l}$ & kJ/kg.k & 2.522 \\
\hline$T 5_{i, h}, T 6_{i, h}$ & $\mathrm{~K}$ & 333 & $C p_{c 2, l}$ & $\mathrm{~kJ} / \mathrm{kg} . \mathrm{k}$ & 2.481 \\
\hline$T 5_{o, h}, T 6_{o, h}$ & $\mathrm{~K}$ & 298 & $C p_{l, 4}$ & kJ/kg.k & 2.388 \\
\hline$T_{o, f 1}, T_{o, f 2}$ & K & 603 & $C p_{l, 5}$ & kJ/kg.k & 2.388 \\
\hline$U_{1}$ & $\mathrm{KW} / \mathrm{m}^{2}$ & 0.432 & $C p_{l, 6}$ & kJ/kg.k & 2.388 \\
\hline
\end{tabular}

\section{a) Energy Balance of Heat Exchanger E 201 (Figure 8a)}

Through this equipment, cold light naphtha is heating and vaporized as a result of the heat transfer from the hot stream of isomerizate as shown in Figure 9. 


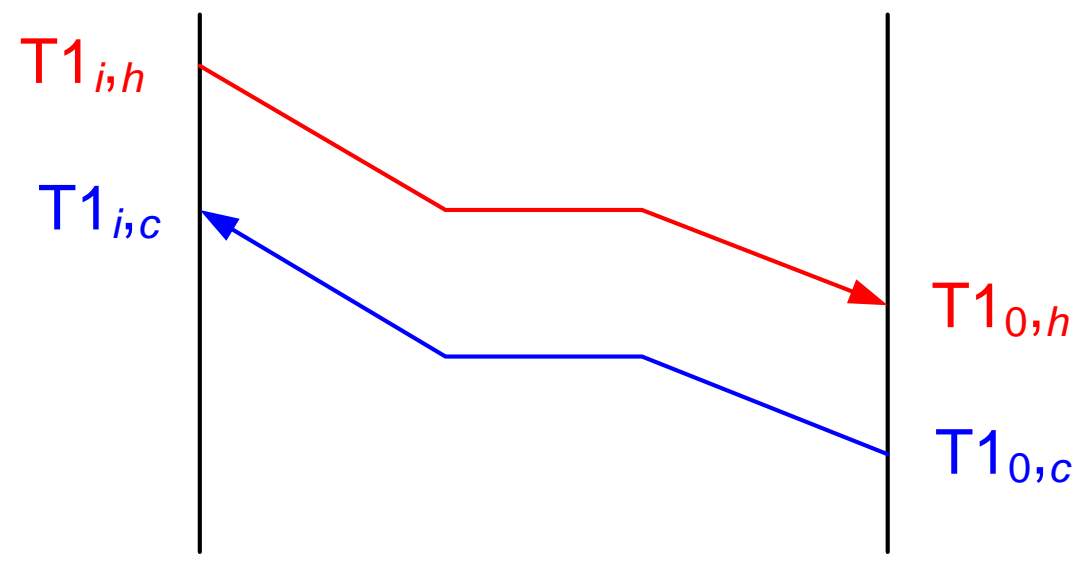

Figure 9: Heat exchanger E201

The area of heat transfer is calculated as a function of outlet reactor temperature, by the following equation:

$$
\begin{aligned}
& A_{t 1}=\frac{Q_{H E 1}}{U_{1} \Delta T_{l m 1}} \\
& \Delta T_{l m 1}=\frac{\Delta T_{1,1}-\Delta T_{1,2}}{\ln \left(\frac{\Delta T_{1,1}}{\Delta T_{1,2}}\right)} \\
& \Delta T_{1,1}=T 1_{i, h}-T 1_{i, c} \\
& \Delta T_{1,2}=T 1_{o, h}-T 1_{o, c}
\end{aligned}
$$

Where:

$T 1_{i, h}$ : The inlet temperature of hot stream into E201, $K$

$T 1_{i, c}$ : The inlet temperature of cold stream into E201 $\mathrm{K}$

$T 1_{o, h}$ : The outlet temperature of hot stream from the heat exchanger E201, $K$

$T 1_{o, c}$ : The outlet temperature of cold from heat exchanger1 (HE1), $K$

$T 1_{i, h}=T$

$\mathrm{T}$ : The outlet reactor temperature, $\mathrm{K}$ (calculated from reactor energy balance equation). $T 1_{o, h} \& T 1_{i, c}$ are given as constant values.

$T 1_{o, c}$ is calculated as a function reactor outlet temperature $\mathrm{T}$ as follow:

Heat loss from hot stream $=$ heat absorbed by cold stream

$$
\begin{aligned}
& T 1_{o, c}=\left(Q_{H E 1}-W_{l n}\left(\lambda_{c 1}+C p_{c 1, l}\left(T 1_{b, c}-T 1_{i, c}\right)+C p_{c 1, v} T 1_{b, c}\right)+W_{H_{2}, \text { in }} C p_{H 2} T 1_{i, c}\right) / \\
& \left(W_{H_{2}, \text { in }} C p_{H 2}+W_{l n} C p_{c 1, v}\right)
\end{aligned}
$$




$$
\begin{gathered}
Q_{H E 1}=W_{i s o}\left(\chi_{h 1}+C p_{h 1, l}\left(T 1_{b, h}-T 1_{i, h}\right)+C p_{h 1, v}\left(T 1_{o, h}-T 1_{b, h}\right)+\right. \\
W_{H_{2}, o} C p_{H 2}\left(T 1_{o, h}-T 1_{i, h}\right)
\end{gathered}
$$

For TIP process (case7), the following heat equations are written as follow:

$$
\begin{aligned}
& T 1_{o, c}=\left(Q_{H E 1}-W_{l n}\left(\lambda_{c 1}+C p_{c 1, l}\left(T 1_{b, c}-T 1_{i, c}\right)+C p_{c 1, v} T 1_{b, c}\right)\right) /\left(W_{l n} C p_{c 1, v}\right) \\
& Q_{H E 1}=W_{i s o}\left(\lambda_{h 1}+C p_{h 1, l}\left(T 1_{b, h}-T 1_{i, h}\right)+C p_{h 1, v}\left(T 1_{o, h}-T 1_{b, h}\right)\right.
\end{aligned}
$$

In this case (case 7) $T 1_{i, h}$ doesn't equal to $T$.

Where:

$T 1_{b, c} \& T 1_{b, h}$ : Boiling temperature of cold and hot stream respectively, $\mathrm{K}$

$\lambda_{c 1} \& \lambda_{h 1}$ : Latent heat of vaporization of cold and hot stream respectively, $\mathrm{kj} / \mathrm{kg}$

$C p_{h 1, l} \& C p_{c 1, l}$ : heat capacity of hot and cold stream respectively as liquid, $\mathrm{kj} /(\mathrm{kg} \mathrm{k})$

$C p_{h 1, v} \& C p_{c 1, v}$ : heat capacity of hot and cold stream respectively as vapor, $\mathrm{kj} /(\mathrm{kg} \mathrm{k})$

\section{b) Energy Balance of Heat Exchanger $E_{202}$ (Figure 8a)}

This equipment is located before the stabilizer (Figure 10), where the hot stream is used to stabilize the isomerizate. Condensation of hot stream and vaporization of the cold stream are occurred based on heat exchanger1.

The area of heat transfer $\left(A_{t 2}\right)$ is calculated as follow:

$$
\begin{aligned}
& A_{t 2}=\frac{Q_{H E 2}}{U_{2} \Delta T_{l m 2}} \\
& \Delta T_{l m 2}=\frac{\Delta T_{2,1}-\Delta T_{2,2}}{\ln \left(\frac{\Delta T_{2,1}}{\Delta T_{2,2}}\right)} \\
& \Delta T_{2,1}=T 2_{i, h}-T 2_{i, c} \\
& \Delta T_{2,2}=T 2_{o, h}-T 2_{o, c} \\
& Q_{H E 2}=W_{i s o}\left(\lambda_{c 2}+C p_{c 2, l}\left(T 2_{b, c}-T 2_{i, c}\right)+C p_{c 2, v}\left(T 2_{o, c}-T 2_{b, c}\right)\right.
\end{aligned}
$$

All parameters above are given as constant. 


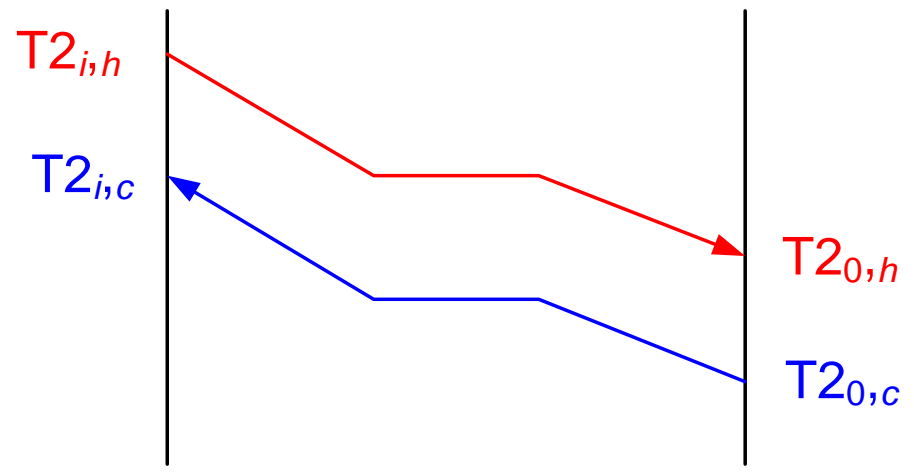

Figure 10: Heat exchanger E202

\section{c) Energy Balance of Heat Exchanger $E_{203}$ (Figure 8a)}

The objective of energy balance is to obtain the heat transfer area $\left(A_{t 3}\right)$ and the amount of steam $\left(W_{\text {steam }}\right)$ which can be described as follow:

$A_{t 3}=\frac{Q_{H E 3}}{U_{3} \Delta T_{l m 3}}$

$\Delta T_{l m 3}=\frac{\Delta T_{3,1}-\Delta T_{3,2}}{\ln \left(\frac{\Delta T_{3,1}}{\Delta T_{3,2}}\right)}$

$\Delta T_{3,1}=T 3_{i, h}-T 3_{i, c}$

$\Delta T_{3,2}=T 3_{0, h}-T 3_{o, c}$

$T 3_{0, c}=T 2_{i, h}$

$T 3_{i, c}=T 2_{0, h}$

...(78)

$Q_{H E 3}=W_{i s o} C p_{v, 3}\left(T 3_{o, c}-T 3_{i, c}\right)$

$W_{\text {steam }}=Q_{H E 3} / \lambda_{H 2 O}$

This equipment is used to rise the bottom stream temperature of stabilizer by steam condensing as shown Figure 11.

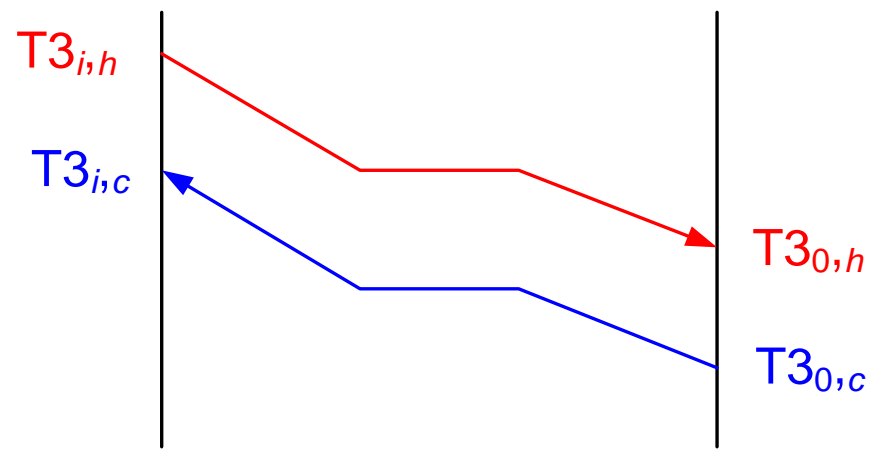

Figure 11: Heat exchanger E203 


\section{d) Energy Balance of Heat Exchangers $E_{204} \& E_{205}$ (Figure 8a)}

These equipment (shown in Figure 12) works as coolers for stabilizing the isomerizate as E204, and light product of stabilizer (E205). Bellow, the equations of $\left(A_{t 4}\right)$ and cooling water rate $\left(W_{H 2 O}\right)$ for heat exchanger4 (E204):

$$
\begin{aligned}
& A_{t 4}=\frac{Q_{H E 4}}{U_{4} \Delta T_{l m 4}} \\
& \Delta T_{l m 4}=\frac{\Delta T_{4,1}-\Delta T_{4,2}}{\ln \left(\frac{\Delta T_{4,1}}{\Delta T_{4,2}}\right)} \\
& \Delta T_{4,1}=T 4_{o, h}-T 4_{i, c} \\
& \Delta T_{4,2}=T 4_{i, h}-T 4_{o, c} \\
& T 4_{i, h}=T 3_{0, h} \\
& Q_{H E 4}=W_{i s o} C p_{l, 4}\left(T 4_{i, h}-T 4_{o, h}\right) \\
& W_{H 2 O}=Q_{H E 4} /\left(C p_{H 2 O}\left(T_{i, H 2 O} T_{o, H 2 O}\right)\right)
\end{aligned}
$$

The same equations are used for E205.

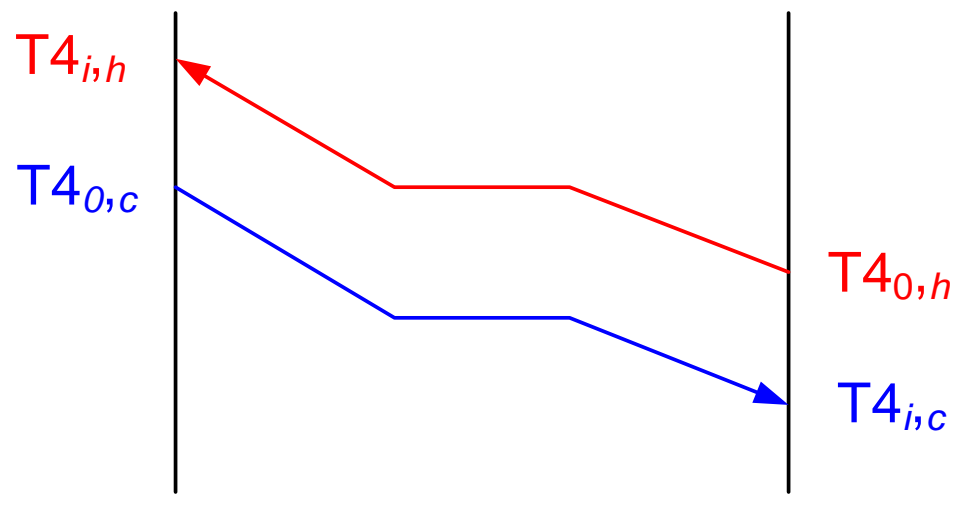

Figure 12: heat exchanger E204 and heat exchanger E205

\section{e) Energy Balance of Heat Exchanger E206_(Figure 8a)}

For the TIP process and the new process proposed here, heat exchanger E206 is used in addition to heat exchangers that are explained above.

$$
\begin{aligned}
& A_{t 6}=\frac{Q_{H E 6}}{U_{6} \Delta T_{l m 6}} \\
& \Delta T_{l m 6}=\frac{\Delta T_{6,1}-\Delta T_{6,2}}{\ln \left(\frac{\Delta T_{6,1}}{\Delta T_{6,2}}\right)} \\
& \Delta T_{6,1}=T 6_{i, h}-T 6_{i, c} \\
& \Delta T_{6,2}=T 6_{o, h}-T 6_{o, c}
\end{aligned}
$$




$$
\begin{aligned}
T 6_{o, c}= & \left(Q_{H E 6}-W_{l n}\left(\chi_{c 6}+C p_{c 6, l}\left(T 6_{b, c}-T 6_{i, c}\right)+C p_{c 6, v} T 6_{b, c}\right)\right) /\left(W_{l n} C p_{c 6, v}\right) \\
Q_{H E l}= & W_{i s o}\left(\lambda_{h 6}+C p_{h 6, l}\left(T 6_{b, h}-T 6_{i, h}\right)+C p_{h 6, v}\left(T 6_{o, h}-T 6_{b, h}\right)+\right. \\
& W_{H_{2}, o} C p_{H 2}\left(T 6_{o, h}-T 6_{i, h}\right) \\
T 6_{i, h}= & T
\end{aligned}
$$

\section{f) Energy Balance of Furnace $(F)$ (Figure 8a)}

The light naphtha stream is entered to the furnace in order to achieve the required reactor inlet temperature. Calculation of the furnace heat duty $\left(Q_{f}\right)$ as a function of reactor inlet temperature is required to complete the cost model.

$Q_{f}=\left(W_{l n} C p_{f, v}+W_{H 2} C p_{H 2}\right)\left(T_{o, f}-T_{i, f}\right)$

$T_{o, f} \& T_{i, f}:$ Outlet and inlet furnace temperature, $\mathrm{K}$

$T_{o, f}=T_{i}$

$T_{i, f}=T 1_{o, c}$

\section{g) Energy Balance of Furnaces $\left(F_{1} \& F_{2}\right)$ (Figure $\left.8 a\right)$}

As shown in the TIP flow sheet (Figure 7) instead of one furnace, there are two furnaces. Their heat duty $\left(Q_{f 1} \& Q_{f 2}\right)$ are calculated as follow:

$Q_{f 1}=\left(W_{l n} C p_{f 1}\right)\left(T_{o, f 1}-T_{i, f 1}\right)$

$T_{o, f} \& T_{i, f}:$ Outlet and inlet furnace temperature, $\mathrm{K}$

$$
\begin{aligned}
& T_{i, f}=T 6_{o, c} \\
& Q_{f 2}=W_{H 2} C p_{H 2}\left(T_{o, f 2}-T_{i, f 2}\right)
\end{aligned}
$$

$T_{o, f 2} \& T_{i, f 2}$ : Outlet and inlet furnace temperature, $\mathrm{K}$

The optimal kinetic parameters of the relevant reactions obtained by Ahmed et al [1] will be employed here to get the optimal operating conditions (temperature, pressure, LHSV, hydrogen ratio), which simultaneously will give the maximum RON, maximum yield and 
minimum cost according to procedure shown in Figure 13 and using the following equations:

$O B J 1=$ Maximization of RON

$O B J 2=$ Maximization of YIELD

$O B J 3=$ Minimization of $O A U C$

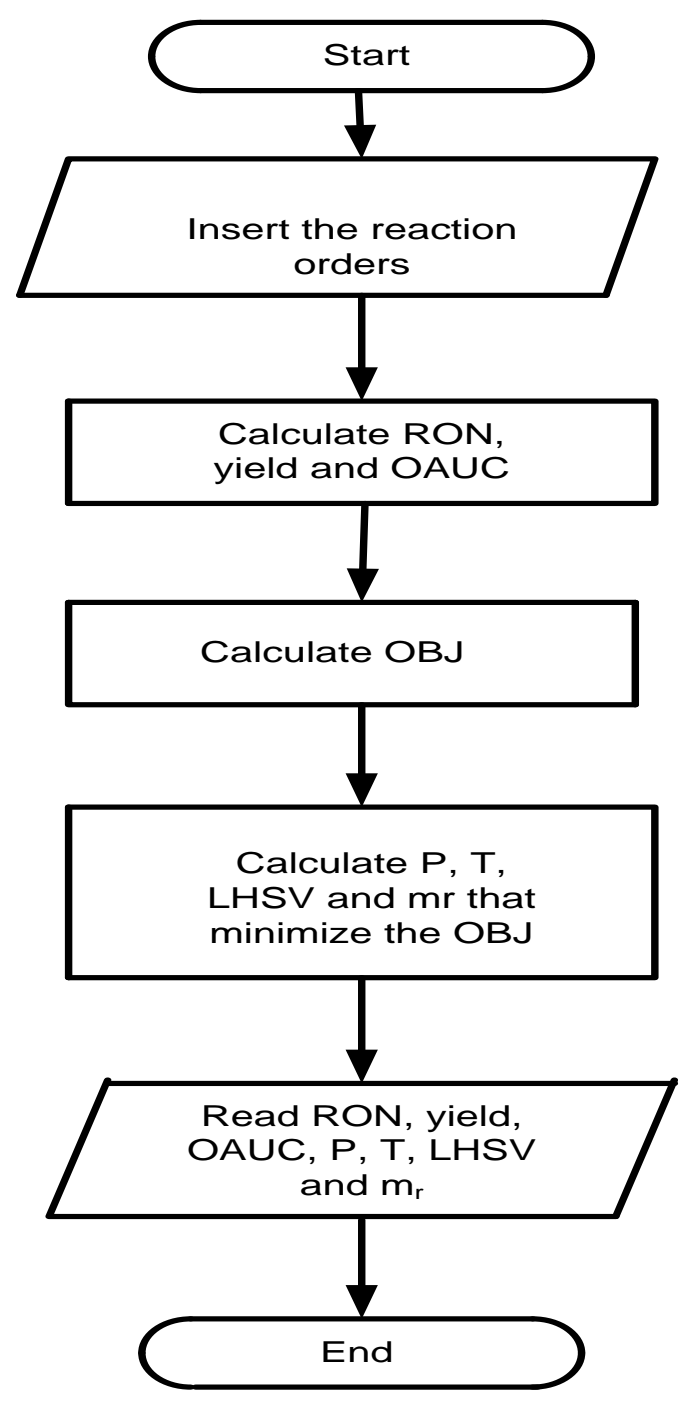

Figure 13: The procedure of isomerization configurations optimization

\subsection{Economic Cost Equations}

The cost estimation is necessary to complete the objective function of the optimization process for each unit (which is applied for all isomerization technologies including the new 
AJAM process [1]. The overall annual cost of process is calculated by using the following relation $[10,11]$ :

Overall Annual Unit Cost $(O A U C, \$ / y r)=$ Annual Unit Capital Cost $(A U C C, \$ / y r)+$ Annual Unit Operating Cost (AUOC, $\$ / y r)$

The annual unit capital cost $(A U C C, \$ / y r)$ are estimated from the total unit capital cost (TUCC, \$), which represents the main equipments cost in the unit process such as reactor, heat exchanger, compressor, furnace, separator and pumps, as the following:

Annual Unit Capital Cost (AUCC, $\$ / y r)=$ Total Unit Capital Cost $(T U C C, \$) \times \frac{\mathrm{i}(1+\mathrm{i})^{\mathrm{N}}}{(1+\mathrm{i})^{\mathrm{N}-1}}$

The total unit capital cost $(T U C C, \$)$ can be estimated from the following equation [12]:

Total Unit Capital Cost (TUCC, \$) = Installed Equipment Capital Cost (IECC, \$) $\times 1.45$

The installed equipment capital cost $(I E C C, \$)$ is different from unit to another due to separation technology that are used. The following equation represents the installed equipment capital cost (IECC, \$) for once through unit:

Installed Equipment Capital Cost (IECC, $\$)=$ Reactor Cost $\left(C_{R}\right)+$ Compressor Cost $\left(C_{c o}\right)$ + Heat exchanger Cost $\left(C_{H E}\right)(1,2,3,4 \& 5)+$ Pumps Cost $\left(C_{p}\right)+$ Furnace Cost $\left(C_{f}\right)+$ Stabilizer Cost $\left.\left(C_{s}\right)\right)+$ separator cost $\left(C_{s}\right)$

Annual unit operating cost $(A U O C, \$ / y r)$ for each unit is calculated from the following equation:

Annual Unit Operating Cost $(A U O C, \$ / y r)=$ Variable Unit Operating Cost $(V U O C, \$ / y r)+$ Fixed Unit Operating Cost (FUOC, $\$ / y r)$ 
Variable Unit Operating Cost $($ VUOC, $\$ / y r)=$ Heating Cost $\left(C_{\text {Heat. }}\right)+$ Compression Cost $\left(C_{\text {comp. }}\right)+$ Cooling $\operatorname{Cost}\left(C_{\text {cool. }}\right)+$ Catalyst Cost $\left(C_{\text {cat }}\right)+$ hydrogen consumption $\operatorname{Cost}\left(C_{\mathrm{H} 2}\right)$ + Pumping Cost $\left(C_{\text {Pump. }}\right)+$ Steam Cost $\left(C_{\text {st }}\right)$

Fixed Unit Operating Cost (FUOC, \$/yr)= Maintenance Cost $\left(f_{1}\right)+$ Operating Labour Cost $\left(f_{2}\right)+$ Laboratory Cost $\left(f_{3}\right)+$ Supervision Cost $\left(f_{4}\right)+$ Plant Overhead Cost $\left(f_{5}\right)+$ Capital Charge Cost $\left(f_{6}\right)+$ Insurance Cost $\left(f_{7}\right)$

\subsubsection{Installed Equipment Capital Cost (IECC, \$)}

The economic cost of each equipment is estimated based on Marshal and Swift index as follow $[10,13,14]$ :

\section{a) $\underline{\text { Reactor } \operatorname{Cost}\left(C_{r}\right)}$}

The reactor cost is calculated as a function to the length $\left(L_{r}\right)$ and diameter $\left(D_{r}\right)$ of the reactor, which are related to the liquid hourly space velocity (LHSV), as follow:

$$
\begin{aligned}
& C_{r}=\left(\frac{M \& S}{280}\right) 101.9 D_{r}^{1.066} L_{r}^{0.802}\left(2.18+F_{c}\right) \\
& F_{c}=F_{m} F_{p}
\end{aligned}
$$

M\&S is taken equal to 1622 [15].

$F_{c}, F_{m}$ and $F_{p}$ : dimensionless factors that are function of the operating pressure and material construction [6].

$$
L_{r}=L+X
$$

$L=\sqrt[3]{\frac{4}{\pi}(L / D) V}$

$V=Q / L H S V$

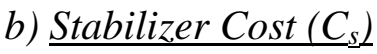

The total distillation column cost is estimated as follow:

$C_{s}=\operatorname{Column} \operatorname{Cost}\left(C_{\text {col. }}\right)+\operatorname{Tray} \operatorname{Cost}\left(C_{\text {tray }}\right)$

Column cost calculated as a function to column length $\left(L_{c}\right)$ and diameter $\left(D_{c}\right)$ : 
$C_{\text {col. }}=\left(\frac{M \& S}{280}\right) 101.9 D_{c}^{1.066} L_{c}^{0.802}\left(2.18+F_{c}\right)$

$F_{c}=F_{m} F_{p}$

$C_{\text {tray }}=\left(\frac{M \& S}{280}\right) 97.24 L_{c} D_{C}^{1.55} F_{C}$

$F_{c}=F_{s}+F_{t}+F_{m}$

$D_{c}$ and $L_{c}$ are calculated from the following equations [13]:

$L_{c}=N_{t}\left(l_{t}+1\right)$

$D_{c}=\sqrt[2]{\frac{4 V_{w}}{\pi \rho_{v c} u_{v}}}$

$u_{v}=\left(-0.171 l_{t}^{2}+0.27 l_{t}-0.047\left[\frac{\left(\rho_{l c}-\rho_{v c}\right)}{\rho_{v c}}\right]^{1 / 2}\right.$

Where:

$V_{w}$ : maximum vapor rate, $\mathrm{Kg} / \mathrm{s}$

$\rho_{v c}:$ vapor density, $\mathrm{kg} / \mathrm{m}^{3}$

$\rho_{v l}:$ liquid density, $\mathrm{kg} / \mathrm{m}^{3}$

$l_{t}$ : tray spacing, $(\mathrm{m})$

$N_{t}$ : tray number, (-)

c) Compressor Cost $\left(C_{c 0}\right)$

The compressor cost related to the reactor pressure is calculated as follow:

$C_{c o .}=\left(\frac{M \& S}{280}\right)(517.5)(b h p)^{0.82}\left(2.11+F_{d}\right)$

The compressor horsepower calculated as follow [16,17]:

$b h p=h p / \eta_{c}$

$h p=\left(\frac{6.843 * 10^{-7}}{\omega}\right) P_{\text {in }} Q_{\text {in }}\left[\left(\frac{P_{\text {out }}}{P_{\text {in }}}\right)^{\omega}-1\right]$

$\omega=\frac{\left(\frac{C P_{H 2}}{C V_{H 2}}-1\right)}{\left(\frac{C P_{H 2}}{C V_{H 2}}\right)}$

$C v_{H 2}=C p_{H 2}-R$

$P_{\text {out }}=\left(P-P_{n s} y_{n s}\right) / y_{H 2}$ 
d) Separator $\operatorname{Cost}\left(C_{\text {sep }}\right)$

$C_{\text {sep }}=\left(\frac{M \& S}{280}\right) 937.63 D_{S}^{1.066} L_{S}^{0.802}$

$D_{S} \& L_{s}$ are the diameter and length of separator, which can be estimated as follows [15]:

To design the horizontal separator vessel, the estimation of the settling velocity of the liquid droplets is necessary.

For satisfactory separation, the required residence time $\left(\tau_{r}\right)=$ actual residence time $\left(\tau_{a}\right)$

Required vapor residence time to settle the droplets to liquid surface $\left(\tau_{r}\right)$ is calculated as follow:

$\tau_{r}=h_{v} / u_{a}$

$h_{v}$ : vapor high, $\mathrm{m}$

$u_{a}$ : settling velocity, $\mathrm{m} / \mathrm{s}$

$h_{v}=0.5 D_{s}$

$u_{a}=0.0105 \sqrt{\frac{\left(\rho_{l n}-\rho_{H 2}\right)}{\rho_{H 2}}}$, (without demister)

$\tau_{a}=L_{s} / u_{v}$

$u_{v}$ : vapor velocity, $\mathrm{m} / \mathrm{s}$

$L_{s}=3 D_{s}$

$u_{v}=Q_{v} / A_{s}$

$A_{s}=\frac{\pi}{4} D_{s}^{2}$

\section{e) Pumps $\operatorname{Cost}\left(C_{p}\right)$}

Due to process flow sheet, there are two pumps, their cost are calculated with respect to naphtha mass rate as follows:

$C_{\text {Pump }}=\left(\frac{M \& S}{280}\right) 9.84 \times 10^{3} F_{C}\left(\frac{Q_{p i}}{4}\right)^{0.55}$

$F_{c}=F_{m} F_{p} F_{T}$

$Q_{p i}$ : power of ith pump, $\mathrm{kW}$

\section{f) $\underline{\text { Heat Exchangers } \operatorname{Cost}\left(C_{H E}\right)}$}

The cost of heat exchanger related to reactor inlet and outlet temperature is calculated as follow: 
$C_{H E}=\left(\frac{\mathrm{M} \& S}{280}\right) 210.78 A_{t}^{0.65}\left(2.29+F_{C}\right)$

$F_{c}=F_{m}\left(F_{d}+F_{p}\right)$

g) Furnace Cost $\left(C_{f}\right)$

$C_{\text {Furn. }}=\left(\frac{M \& S}{280}\right) 5.52 \times 10^{3} Q_{F}^{0.85}\left(1.27+F_{C}\right)$

$F_{c}=F_{m}+F_{p}+F_{d}$

h) $\underline{\text { Adsorber } \operatorname{Cost}\left(C_{a d}\right)}$

Economic cost of adsorber column is calculated (for only process that use molecular sieve technology) as follow:

$C_{r}=\left(\frac{M \& S}{280}\right) 101.9 D_{r}^{1.066} L_{r}^{0.802}\left(2.18+F_{c}\right)$

$F_{c}=F_{m} F_{p}$

$L=\sqrt[3]{\frac{4}{\pi}(L / D) V}$

$L / D$ : length to diameter bed ratio, (-)

$V$ : bed volume, $\left(\mathrm{m}^{3}\right)$

$V=M_{5 A} / \rho_{5 A}$

The ratio of $l_{d} / D_{d}$ equals to 1.25 according to Holcombe [7].

The amount of catalyst $\left(M_{5 A}\right)$ is calculated by scaling down of the beds used in the scheme designed as shown below [6]:

\section{Original}

$33000(\mathrm{~kg}$ of $5 \mathrm{~A})$

$M_{5 A}(\mathrm{~kg}$ of $5 \mathrm{~A})$

\section{This case}

$18450(\mathrm{~kg} / \mathrm{hr}$ of n-paraffins received $)$

$M_{n p}(\mathrm{~kg} / \mathrm{hr}$ of n-paraffins received $)$

The rate of normal paraffins received $\left(M_{n p}\right)$ is obtained by simulation process for each technology. 


\subsubsection{Fixed Unit Operating Cost (FUOC, \$/yr)}

Each variable of fixed unit operating cost (FUOC) are estimated as follow [7, 10]:

- Maintenance Cost $\left(f_{1}\right)$ : It includes the cost of equipment spares and the cost of labour needed for the unit maintenance. Typically, the annual maintenance cost is taken (5-15\%) of the installed capital cost.

- Operating Labour Cost $\left(f_{2}\right)$ : It includes the cost of the person needed to operate the plant. The value is taken $15 \%$ of the total annual operating cost.

- Laboratory Cost $\left(f_{3}\right)$ : It includes the desired laboratory analyses for process quality control. The value of laboratory cost is about 20 to $30 \%$ of the operating labour cost.

- Supervision Cost $\left(f_{4}\right)$ : It involves the direct supervision of operation and the management directly linked with operating the plant. The value is about $25 \%$ of the labour cost.

- Plant Overhead Cost $\left(f_{5}\right)$ : It involves all the general costs linked with operating the plant that are not involved with other headings (such as plant, offices, security, canteen, medical, safety and staff). This value are about (50-100\%) of the labour cost.

- Capital Charge Cost $\left(f_{6}\right)$ : It is recovered as a depreciation charge. The value can be taken as $10 \%$ of the total unit capital cost.

- Insurance $\operatorname{Cost}\left(f_{7}\right)$ : This value is often taken as (1-2\%) of the total unit capital cost.

\subsubsection{Variable Unit Operating Cost (VUOC, \$/yr)}

The VUOC is calculated use the following equations:

\section{a) Compression Cost $\left(C_{\text {comp. }}\right)$}

The compressor can be estimated as follow based on the motor efficiency at $90 \%$ with a power price of $0.062 \$ / \mathrm{kWh}[16]$ :

$C_{\text {comp. }}(\$ / y r)=\left(\frac{b h p(h p)}{0.9}\right)\left(\frac{1 k W}{1.341 h p}\right)\left(\frac{0.062 \$}{k W h}\right)\left(\frac{24 h}{1 d a y}\right)\left(\frac{342}{y r}\right)$

b) $\underline{\text { Heating } \operatorname{Cost}}\left(C_{\text {Heat. }}\right)$

$C_{\text {Heat. }}(\$ / y r)=\left(Q_{F}(k W)\right)\left(\frac{0.062 \$}{k W h}\right)\left(\frac{24 h}{1 \text { day }}\right)\left(\frac{342}{1 y r}\right)$

c) Pumping Cost $\left(C_{\text {Pump. }}\right)$

$C_{\text {pump. }}(\$ / \mathrm{yr})=\left(Q_{p}(k W)\right)\left(\frac{0.062 \$}{k W h}\right)\left(\frac{24 h}{1 \text { day }}\right)\left(\frac{342}{y r}\right)$ 


\section{d) $\underline{\text { Cooling Cost }}\left(C_{\text {cool. }}\right)$}

It is calculated by the following equation with a price of cooling water $(0.0035 \$ / \mathrm{kg})$ [17]:

$C_{\text {cool. }}(\$ / y r)=\left(W_{H 2 O}\left(\frac{k g}{h}\right)\right)\left(\frac{0.00175 \$}{k g}\right)\left(\frac{24 h}{1 d a y}\right)\left(\frac{342}{y r}\right)$

\section{e) Hydrogen Consumption Cost $\left(C_{H 2}\right)$}

It can be calculated by the following equation with a price of hydrogen at $0.49 \$ / \mathrm{m}^{3} \mathrm{H}_{2}$ [18]:

$C_{H 2}(\$ / y r)=\left(\frac{0.49 \$}{m^{3}}\right)\left(\frac{m^{3}}{\rho_{H 2} k g}\right)\left(\frac{W_{H_{2} C} k g}{h r}\right)\left(\frac{24 h}{1 \text { day }}\right)\left(\frac{344}{y r}\right)$

$W_{\mathrm{H}_{2} \mathrm{C}}$ : weight rate of hydrogen consumption, $(\mathrm{kg} / \mathrm{hr})$

$W_{H_{2}, C}=W_{H_{2}, \text { in }}-W_{H_{2}, O}$

$M$ :total moles interred the reactor, mol

$W_{H_{2}, \text { in }}=2 * R * \frac{W_{l n}}{M w t_{l n}}$

$W_{H_{2}, O}=2 * y_{H 2} * M$

$W_{\mathrm{H}_{2}, \text { in }} \boldsymbol{\&} W_{\mathrm{H}_{2}, \mathrm{O}}$ : weight rate of reactor inlet and outlet hydrogen, $(\mathrm{kg} / \mathrm{hr})$

\section{f) $\underline{\text { Catalyst Cost }}\left(C_{\text {cat. }}\right)$}

$C_{\text {cat. }}(\$ / \mathrm{yr})=\left(V \mathrm{~m}^{3}\right)\left(\frac{96 \$}{\mathrm{~kg}}\right)\left(\frac{\rho_{\text {cat }} \mathrm{kg}}{\mathrm{m}^{3}}\right)\left(\frac{1}{t_{\text {cat }} y r}\right)$

The catalyst price is taken $96 \$ / \mathrm{kg}$ [19], $t_{\text {cat }}$ is the catalyst life time taken by 10 years [2].

\section{g) Zeolite-5A $\operatorname{Cost}\left(C_{5 A}\right)$}

The price of 5A Iso-sieve Zeolite is equal to $2 \$ / \mathrm{kg}$ [19]

$C_{5 A}=\left(M_{5 A}\right)(k g)\left(\frac{2 \$}{k g}\right)$

\section{h) $\underline{\text { Steam } \operatorname{Cost}}\left(C_{\text {st. }}\right)$}

It is calculated by the following equation with a price of steam equals to $0.018 \$ / \mathrm{kg}$ [20]:

$C_{\text {st. }}(\$ / y r)=\left(W_{\text {st. }}\left(\frac{k g}{h}\right)\right)\left(\frac{0.00259 \$}{k g}\right)\left(\frac{24 h}{1 \text { day }}\right)\left(\frac{342}{y r}\right)$ 


\section{Performance Evaluation of Alternative Technologies}

All the results have been obtained by using the feed stock composition presented in Table 5 .

Table 5: Inlet and outlet composition of isomerization reactor which represents industrial data of Baiji North Refinery

\begin{tabular}{lcc}
\hline \multicolumn{1}{c}{ Hydrocarbon components } & inlet & outlet \\
\hline n-Butane (nC4) & 4.253 & 1.970 \\
\hline n-Pentane( nC5) & 25.977 & 18.362 \\
\hline n-Hexane(nC6) & 14.320 & 7.597 \\
\hline n-Heptane (nC7) & 2.816 & 0.059 \\
\hline i-Butane (iC4) & 0.353 & 0.963 \\
\hline i-pentane (iC5) & 20.652 & 35.689 \\
\hline 2,2 Di Methyl Butane (2,2DMB) & 0.451 & 7.356 \\
\hline 2,3 Di Methyl Butane (2,3DMB) & 1.472 & 3.092 \\
\hline 2 Methyl Pentane (2MP) & 9.311 & 12.597 \\
\hline 3 Methyl Pentane (3MP) & 7.294 & 8.599 \\
\hline i-heptane (iC7) & 5.084 & 0.250 \\
\hline Cyclo Pentane (CP) & 1.312 & 1.369 \\
\hline Methyl Cyclo Pentane (MCP) & 2.574 & 1.072 \\
\hline Cyclo Hexane (CH) & 1.270 & 0.316 \\
\hline Benzene (C6) & 0.433 & 0.000 \\
\hline
\end{tabular}

\subsection{Optimal Case Studies}

Case Study 1: Once Through Process - Figure 1 (BNR)

The results presented in Table 6 show that the lowest RON (79.709) have been obtained from once through process because there is no normal paraffins recycle or branched paraffins by-pass is used which increasing the equilibrium conversion. Also, its cost $(\mathrm{OAUC}=10654036$ ) is low because owing to increase the equipment capacity and utilities due to the recycle used [3].

Table 6: Optimal operating conditions, economic and performance variables results of once through process (BNR Process)

\begin{tabular}{ccc}
\hline Variables & Unit & Value \\
\hline $\boldsymbol{O A U C}$ & $\$ / \mathrm{yr}$ & 10653807 \\
\hline RON & $(-)$ & 79.452 \\
\hline Yield & $(\%)$ & 97.683 \\
\hline T & $\mathrm{K}$ & 524.31 \\
\hline $\mathbf{P}$ & $\mathrm{MPa}$ & 2.4 \\
\hline LHSV & $\mathrm{hr}^{-1}$ & 1.51 \\
\hline $\boldsymbol{m}_{\boldsymbol{r}}$ & $\mathrm{mol} \mathrm{H}_{2} / \mathrm{mol} \mathrm{HC}$ & 3.31 \\
\hline $\boldsymbol{C P U}$ time & $\mathrm{sec}$ & 0.718
\end{tabular}




\section{Case Study 2: DIP Process (Figure 2)}

From the results presented in Table 7 and in comparison with case once, adding of DIP to the base unit increases the RON (81.647) by $4.64 \%$ due to increase the normal pentane conversion, and OAUC (9390270\$) was decreased by $11.83 \%$ owing to reduce the equipments sizes, hydrogen make up, catalyst amount, power and energy required because $20 \%$ of the feed stock have been separated before isomerizing it.

Table 7: Optimal operating conditions, cost and performance variables results of process with DIP

\begin{tabular}{ccc}
\hline Variables & Unit & Value \\
\hline $\boldsymbol{O A U \boldsymbol { C }}$ & $\$ / \mathrm{yr}$ & 9390270.0 \\
\hline RON & $(-)$ & 81.647 \\
\hline Yield & $(\%)$ & 97.78 \\
\hline $\mathbf{T}$ & $\mathrm{K}$ & 522.83 \\
\hline $\mathbf{P}$ & $\mathrm{MPa}$ & 2.261 \\
\hline $\mathbf{L H S V}$ & $\mathrm{hr}^{-1}$ & 1.402 \\
\hline $\boldsymbol{m}_{\boldsymbol{r}}$ & $\mathrm{mol} \mathrm{H}_{2} / \mathrm{mol} \mathrm{HC}$ & 3.29 \\
\hline $\boldsymbol{C P U}$ time & $\mathrm{sec}$ & 0.720 \\
\hline
\end{tabular}

\section{Case Study 3: DIH Process (Figure 3)}

Based on the results shown in Table 8 and in comparison with case 1, increasing the RON (86.21) in this case leads to increase the OAUC $(17249371 \$)$ due to increase the capital and operating cost as a result of increasing the feed stock by $26.36 \%$ in comparison with those obtained in once through process beside the cost of DIH process.

Table 8: Optimal operating conditions, cost and performance variables results of process with DIH

\begin{tabular}{ccc}
\hline Variables & Unit & Value \\
\hline $\boldsymbol{O A} \boldsymbol{C} \boldsymbol{C}$ & $\$ / \mathrm{yr}$ & 17249371 \\
\hline RON & $(-)$ & 86.21 \\
\hline Yield & $(\%)$ & 96.827 \\
\hline $\mathbf{T}$ & $\mathrm{K}$ & 524.65 \\
\hline $\mathbf{P}$ & $\mathrm{MPa}$ & 2.371 \\
\hline $\mathbf{L H S V}$ & $\mathrm{hr}^{-1}$ & 1.429 \\
\hline $\boldsymbol{m}_{\boldsymbol{r}}$ & $\mathrm{mol} \mathrm{H}_{2} / \mathrm{mol} \mathrm{HC}$ & 3.21 \\
\hline $\boldsymbol{C P U}$ time & $\mathrm{sec}$ & 1.420 \\
\hline
\end{tabular}

\section{Case Study 4: DIP-DIH Process (Figure 4)}

The results of this case are shown in Table 9. As proven and explained in case two, the use of DIP has a positive effect on the maximum RON and minimum cost. Using of DIP can 
reduce the $O A U C(16184704 \$)$ by $6.19 \%$ in comparison with case 3. Also the RON (88.292) increased by 2.082 compared with case 3 due to use DIP, so this feed stock composition and using of isomerization process with DIP and DIH technologies is preferred in comparison with the isomerization process with DIH.

Table 9: Optimal operating conditions, cost and performance variables results of isomerization process with DIP\& DIH

\begin{tabular}{ccc}
\hline Variables & Unit & Value \\
\hline $\boldsymbol{O A} \boldsymbol{C} \boldsymbol{C}$ & $\$ / \mathrm{yr}$ & 16184704 \\
\hline RON & $(-)$ & 88.292 \\
\hline Yield & $(\%)$ & 97.51 \\
\hline $\mathbf{T}$ & $\mathrm{K}$ & 523.4 \\
\hline $\mathbf{P}$ & $\mathrm{MPa}$ & 2.373 \\
\hline LHSV & $\mathrm{hr}^{-1}$ & 1.493 \\
\hline $\boldsymbol{m}_{\boldsymbol{r}}$ & $\mathrm{mol} \mathrm{H}_{2} / \mathrm{mol} \mathrm{HC}$ & 3.847 \\
\hline $\boldsymbol{C P U}$ time & $\mathrm{sec}$ & 0.281 \\
\hline
\end{tabular}

\section{Case Study 5: Ipsorb Process (Figure 5)}

Total paraffins recycled are acquired with recycling $50 \%$ of the total normal paraffin in the feed stock leading to increase the reactor feed stock by $33 \%$ in comparison with once through process.

As shown in Table 10 and in comparison with case 1, the use of molecular sieve technique increases the RON (88.273) of isomerizate by 8.81, but such increases is associated with high OAUC (17641911\$) due to high recycle rate although because the total paraffin recycled is acquired with recycling $50 \%$ of the total normal paraffin in the feed stock which leading to increase the reactor feed stock by $33 \%$ in comparison with once through process. Also, it is found that Ipsorb has the minimum OAUC in comparison with Hexorb and TIP process due to presence of DIP equipment which reduces the feed rate.

Table 10: Optimal operating conditions, cost and performance variables results of Ipsorb process

\begin{tabular}{ccc}
\hline Variables & Unit & Value \\
\hline $\boldsymbol{O A} \boldsymbol{U} \boldsymbol{C}$ & $\$ / \mathrm{yr}$ & 17641911 \\
\hline RON & $(-)$ & 88.273 \\
\hline Yield & $(\%)$ & 97.27 \\
\hline $\mathbf{T}$ & $\mathrm{K}$ & 524.2 \\
\hline $\mathbf{P}$ & $\mathrm{MPa}$ & 2.35 \\
\hline LHSV & $\mathrm{hr}^{-1}$ & 1.419 \\
\hline $\boldsymbol{m}_{\boldsymbol{r}}$ & $\mathrm{mol} \mathrm{H}_{2} / \mathrm{mol} \mathrm{HC}$ & 3.39 \\
\hline $\boldsymbol{C P U}$ time & $\mathrm{sec}$ & 3.570 \\
\hline
\end{tabular}




\section{Case Study 6: Hexorb Process (Figure 6)}

In Hexorb process (Table 11), the RON (90.04) has increased by 1.767 in comparison with Ipsorb process due to use DIH technique that increases the yield of 2,2DMB and 2,3DMB which have high RON. But such technique cause high increase in the feed stock as a result of methyl pentanes recycling and this scheme having the highest operating and capital cost. Although this technique gave the highest optimal value of RON compared with last technologies, such scheme exclusives to laboratory scale owing to its high OAUC (22886940\$).

Table 11: Optimal operating conditions, cost and performance variables results of Hexorb process

\begin{tabular}{ccc}
\hline Variables & Unit & Value \\
\hline $\boldsymbol{O A} \boldsymbol{C} \boldsymbol{C}$ & $\$ / \mathrm{yr}$ & 22886940 \\
\hline RON & $(-)$ & 90.04 \\
\hline Yield & $(\%)$ & 96.89 \\
\hline T & $\mathrm{K}$ & 522.9 \\
\hline $\mathbf{P}$ & $\mathrm{MPa}$ & 2.382 \\
\hline $\mathbf{L H S V}$ & $\mathrm{hr}^{-1}$ & 1.51 \\
\hline $\boldsymbol{m}_{\boldsymbol{r}}$ & $\mathrm{mol} \mathrm{H}_{2} / \mathrm{mol} \mathrm{HC}$ & 3.412 \\
\hline $\boldsymbol{C P U}$ time & $\mathrm{sec}$ & 0.717 \\
\hline
\end{tabular}

\section{Case Study 7: TIP Process (Figure 7)}

As noticed from the results presented in Table 12 bellow, it has been observed that recycling $22 \mathrm{ton} / \mathrm{hr}$ of normal paraffins leads to increase the value of RON (88.17). This scheme has an economic cost $(\mathrm{OAUC}=19786370 \$)$ higher than Ipsorb process $(17641911 \$)$ and lower than Hexorb process $(22886510 \$)$. This behavior is attributed as follows: in Ipsorb process, the presence of DIP reduces the amount of recycled normal paraffins, while in Hexorb process, the presence of DIH increases the amount of recycled normal paraffins in addition to methyl pentanes recycle by DIH.

Table 12: Optimal operating conditions, cost and performance variables results of TIP process

\begin{tabular}{ccc}
\hline Variables & Unit & Value \\
\hline $\boldsymbol{O A} \boldsymbol{A} \boldsymbol{C}$ & $\$ / \mathrm{yr}$ & 19786370 \\
\hline RON & $(-)$ & 88.17 \\
\hline Yield & $(\%)$ & 97.06 \\
\hline T & $\mathrm{K}$ & 521.72 \\
\hline $\mathbf{P}$ & $\mathrm{MPa}$ & 2.317 \\
\hline $\mathbf{L H S V}$ & $\mathrm{hr}^{-1}$ & 1.498 \\
\hline $\boldsymbol{m}_{\boldsymbol{r}}$ & $\mathrm{mol} \mathrm{H}_{2} / \mathrm{mol} \mathrm{HC}$ & 3.18 \\
\hline $\boldsymbol{C P U}$ time & $\mathrm{sec}$ & 1.388 \\
\hline
\end{tabular}




\section{Case Study 8: AJAM Isomerization Process (Figure 8)}

The results of the recently developed AJAM process are presented in Table 13. The highest RON and highest yield are obtained by using this new configuration process in comparison with those obtained by traditional methods. Increasing in RON (90.81) (belong to the presence of benzene component in the final product that hydrogenated in others technologies. While, increasing the yield (99.20) belong to decrease the reactor feed stock rate by $48.34 \%$ weight percent than of once through process.

Table 13: Optimal operating conditions, cost and performance variables results of AJAM process

\begin{tabular}{ccc}
\hline Variables & Unit & Value \\
\hline $\boldsymbol{O A} \boldsymbol{C} \boldsymbol{C}$ & $\$ / \mathrm{yr}$ & 15212319 \\
\hline RON & $(-)$ & 90.81 \\
\hline Yield & $(\%)$ & 99.20 \\
\hline T & $\mathrm{K}$ & 521.09 \\
\hline P & $\mathrm{MPa}$ & 2.104 \\
\hline LHSV & $h r^{-1}$ & 1.503 \\
\hline $\boldsymbol{m}_{\boldsymbol{r}}$ & $(-)$ & 3.46 \\
\hline $\boldsymbol{C P U}$ time & $\mathrm{sec}$ & 0.764 \\
\hline
\end{tabular}

Also, the minimum OAUC required $(15212319 \$)$ in comparison with others molecular sieve technologies is the lowest owning to reduce the feed rate leading to decrease the hydrogen make up, heating required, catalyst and all equipment capacities as shown in Table 14.

Table 14: AJAM, TIP and OT process comparison

\begin{tabular}{lccc}
\hline \multicolumn{1}{c}{ Variables } & $\begin{array}{c}\text { AJAM } \\
\text { Process }\end{array}$ & TIP & Once through \\
\hline Reactor feed rate $(\mathbf{T o n} / \mathbf{h r})$ & 40.6 & 101.27 & 75.841 \\
\hline Heating required $(\mathbf{k W})$ & 5033.5 & 7099.1 & 5652.38 \\
\hline Reactor bed volume $\left(\boldsymbol{m}^{\mathbf{3}}\right)$ & 39.25 & 89.64 & 74.20 \\
\hline Hydrogen make up $(\mathbf{T o n} / \mathbf{h r})$ & 0.762 & 1.621 & 1.378 \\
\hline
\end{tabular}

\section{Energy Saving Opportunity in AJAM Process}

Having found that AJAM process outweigh other existing isomerization processes (using same catalyst in the reactor), we look at the energy saving opportunity of the AJAM process based on pinch technology [21].

In order to develop a method of energy recovery and the best rearrangement of heat exchangers network, several efforts have been done in recent decay [22]. 


\subsection{Minimum Temperature Difference Calculation}

In case 8 and according to pinch theory, there are six streams: three hot streams need to cool and three cold streams need to heat. Each stream starts from temperature of source $\left(T_{s}\right)$ and then cooled or heated to target temperature $\left(T_{t}\right)$ as shown in Table 15 . The heat capacity $\mathrm{CP}$ $\left(\mathrm{kW} /{ }^{\circ} \mathrm{C}\right)$ of each stream is given as follow:

$C P=W^{*} C p$

Where:

$C p$ : The heat capacity of stream, $\mathrm{kJ} /\left(\mathrm{kg} .{ }^{\circ} \mathrm{C}\right)$

$W$ : mass flow rate of stream, $\mathrm{kg} / \mathrm{s}$

By using the data in Table 16 and following the procedure presented by Linnhoff and Hindmarsh [21], Figure 14 is plotted.

Table 15: Dimensionless factors values

\begin{tabular}{lcccccc}
\hline \multicolumn{7}{c}{ Dimensionless factors } \\
\hline equipments & $\boldsymbol{F}_{\boldsymbol{m}}$ & $\boldsymbol{F}_{\boldsymbol{p}}$ & $\boldsymbol{F}_{\boldsymbol{d}}$ & $\boldsymbol{F}_{\boldsymbol{T}}$ & $\boldsymbol{F}_{\boldsymbol{t}}$ & $\boldsymbol{F}_{\boldsymbol{S}}$ \\
\hline Reactor & 3.67 & 1.275 & - & - & - & - \\
\hline Stabilizer column & 3.67 & 1.12 & - & - & - & - \\
\hline Pump1 & 1 & - & - & 1 & - & - \\
\hline Pump2 & 1 & 1.5 & - & 1 & - & - \\
\hline Cooler1 \&2 & 3.75 & 0.1 & 0.85 & - & - & - \\
\hline Heat exchanger1 & 3.75 & 0.25 & 0.85 & - & - & - \\
\hline Heat exchanger2 & 3.75 & 0.1 & 0.85 & - & - & - \\
\hline Heat exchanger3 & 3.75 & 0.1 & 0.85 & - & - & - \\
\hline Furnace & 0.75 & 0.0 & 1 & - & - & - \\
\hline Pressure vessel & 1 & 1.275 & - & - & - & - \\
\hline Tray (stabilizer) & 1.7 & - & - & - & 0.0 & 1.4 \\
\hline Compressor & 1 & - & - & - & - & - \\
\hline
\end{tabular}

Table 16: Data required for heat integration problem

\begin{tabular}{cccccccc}
\hline \multirow{2}{*}{$\begin{array}{c}\text { Stream } \\
\text { number }\end{array}$} & Type & \multicolumn{3}{c}{$\mathbf{C P}\left(\mathbf{k W} /{ }^{\mathbf{}} \mathbf{C}\right)$} & \multirow{2}{*}{$\boldsymbol{T}_{\boldsymbol{s}},{ }^{\mathbf{0}} \mathbf{C}$} & $\boldsymbol{T}_{\boldsymbol{t}},{ }^{\mathbf{0}} \mathbf{C}$ & $\begin{array}{c}\text { Heat } \\
\text { load }\end{array}$ \\
\cline { 3 - 6 } & & Vapor & $\lambda / \boldsymbol{T}_{\boldsymbol{b}}$ & Liquid & & & \\
\hline $\mathbf{1}$ & Hot & 60.95 & 32.66 & 57.42 & 305 & 40 & 21446.4 \\
\hline $\mathbf{2}$ & Hot & 48.09 & - & - & 305 & 250 & 2645 \\
\hline $\mathbf{3}$ & Hot & 46.08 & 16 & 44.65 & 280 & 40 & 13877 \\
\hline $\mathbf{4}$ & Cold & 60.32 & 32.66 & 57.2 & 40 & 305 & 23271 \\
\hline $\mathbf{5}$ & Cold & 43.71 & 16 & 42.31 & 40 & 305 & 11703 \\
\hline $\mathbf{6}$ & Cold & 13.98 & - & - & 70 & 305 & 3284 \\
\hline
\end{tabular}




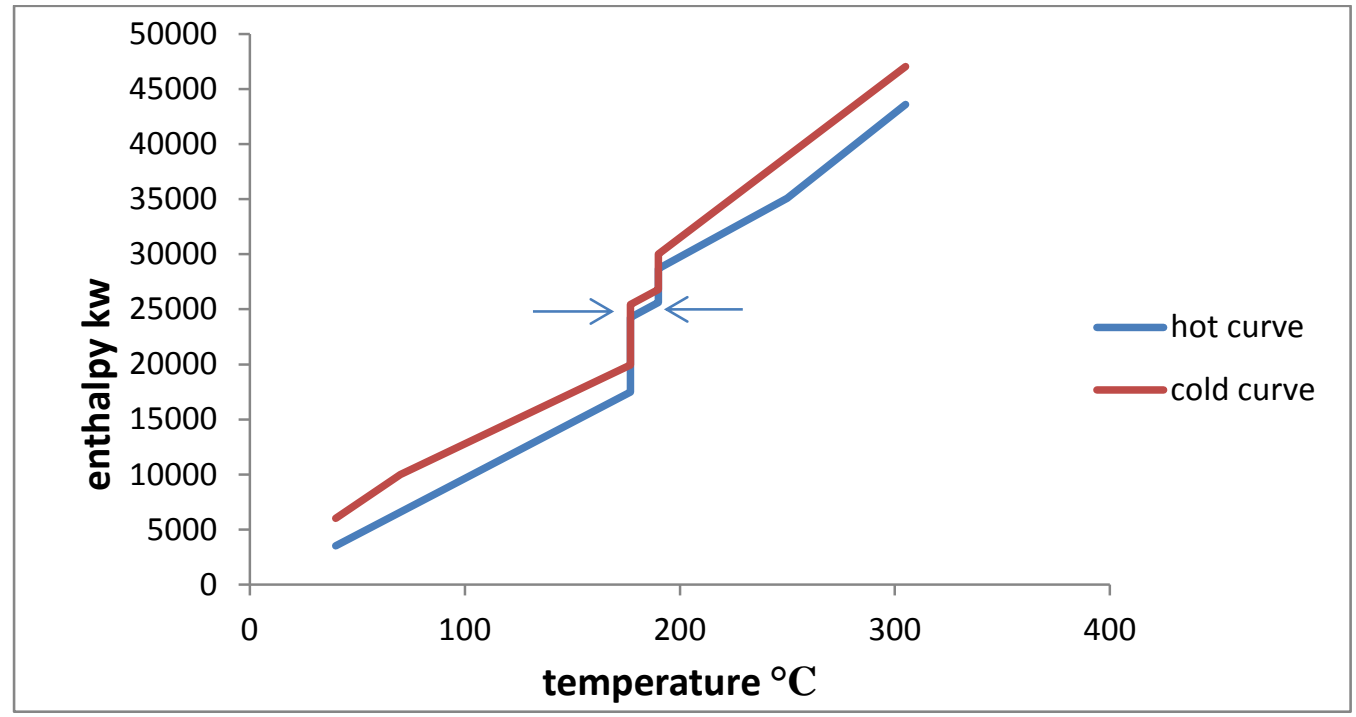

Figure 14: Cold and Hot streams composite curves

From plot of composite streams in Figure 14, the pinch acquires between $190^{\circ} \mathrm{C}$ on the hot stream and $177^{\circ} \mathrm{C}$ on the cold stream with minimum temperature $(\Delta T)$ difference equals to $13^{\circ} \mathrm{C}$

\subsection{The Heat Exchanger Network Design}

The analysis carried out in Figure 14 has shown that the pinch can be occurred where the cold streams are at $177^{\circ} \mathrm{C}$ and the hot $190^{\circ} \mathrm{C}$. Figure 15 shows the grid representation of the six streams, the dotted vertical lines represent the pinch and they separate the grid into two regions below and above the pinch [21].

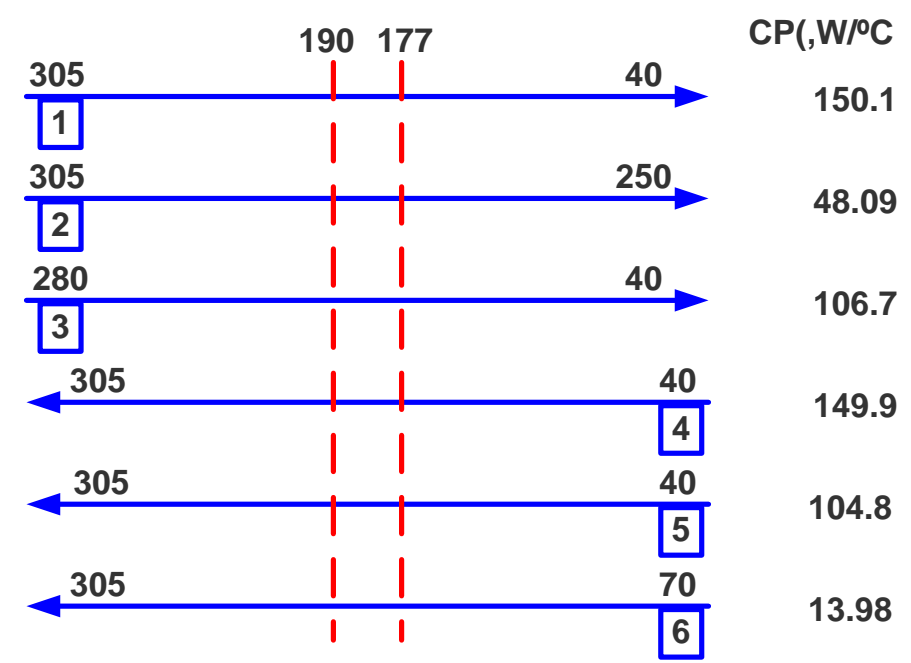

Figure 15: Grid of the six streams 
The maximum recovery of energy is obtained if no cooling is utilized above the pinch. This means that the heat capacity of hot stream should be equal to or less than heat capacity of the cold stream above the pinch, and equals to or high than heat capacity of the cold stream below the pinch.

According to values of heat capacities, stream 1 is matched with stream 4 , stream 2 is matched with stream 6 and stream 3 is matched with stream 5. Due to the equality of $\mathrm{CP}$ values for stream 1 with stream 4 and stream 3 with stream 5, same network design is used below and above the pinch. The heat duty is calculated by following equation:

$Q_{i}=C P_{v}\left(T_{s}-T_{b}\right)+W \lambda+C P_{l}\left(T_{b}-T_{t}\right)$

Where, $i$ is the stream no.

\section{Matching of steams 1 and 4, the following points are observed:}

$\checkmark$ The heat required to rise temperature of stream 4 from $40^{\circ} \mathrm{C}$ to $305^{\circ} \mathrm{C}$ equal to $21922.2 \mathrm{~kW}$

$\checkmark$ The transferring heat required to bring stream 1 to $40^{\circ} \mathrm{C}$ is equal to $21308.28 \mathrm{~kW}$.

$\checkmark$ The transferring heat required to bring stream 1 to $53^{\circ} \mathrm{C}$ is equal to $20461.40 \mathrm{~kW}$.

$\checkmark$ Heating required for stream $4=21922.2-20461.4=1460.8 \mathrm{~kW}$.

Cooling required for stream $1=21308.28-20461.4=846.88 \mathrm{~kW}$.

\section{Matching of steams 2 and 6, the following points are observed:}

$\checkmark$ The full amount of heat transferring from stream 2 to stream 6 is equal to $1883.64 \mathrm{~kW}$.

$\checkmark$ The heat required to bring stream 6 to target temperature is equal to $3284.96 \mathrm{~kW}$.

$\checkmark$ Heating required for stream $6=1401.36 \mathrm{~kW}$.

Matching of steams 3 and 4, the following points are observed:

$\checkmark$ The heat required to rise temperature of stream 5 from $40^{\circ} \mathrm{C}$ to $305^{\circ} \mathrm{C}$ equal to 14974.8 $\mathrm{kW}$.

$\checkmark$ The transferring heat required to bring stream 3 to $40^{\circ} \mathrm{C}$ is equal to $13976.23 \mathrm{~kW}$.

$\checkmark$ The transferring heat required to bring stream 3 to $53^{\circ} \mathrm{C}$ is equal to $13395.78 \mathrm{~kW}$.

$\checkmark$ Heating required for stream $5=14974.8-13395.78=1579.02 \mathrm{~kW}$.

$\checkmark$ Cooling required for stream $3=13976.23-13395.78=580.45 \mathrm{~kW}$.

The results above are represented by the network presented in Figure 16. 
According to the network shown above, the flow diagram of new process proposed (Fig. 8) is modified by adding a heat exchanger equipment before the second furnace (F202) reducing the heat duty supply to $6^{\text {th }}$ stream in Figures (16 and 17) represent the modifying flow diagram of new isomerization proposed here.

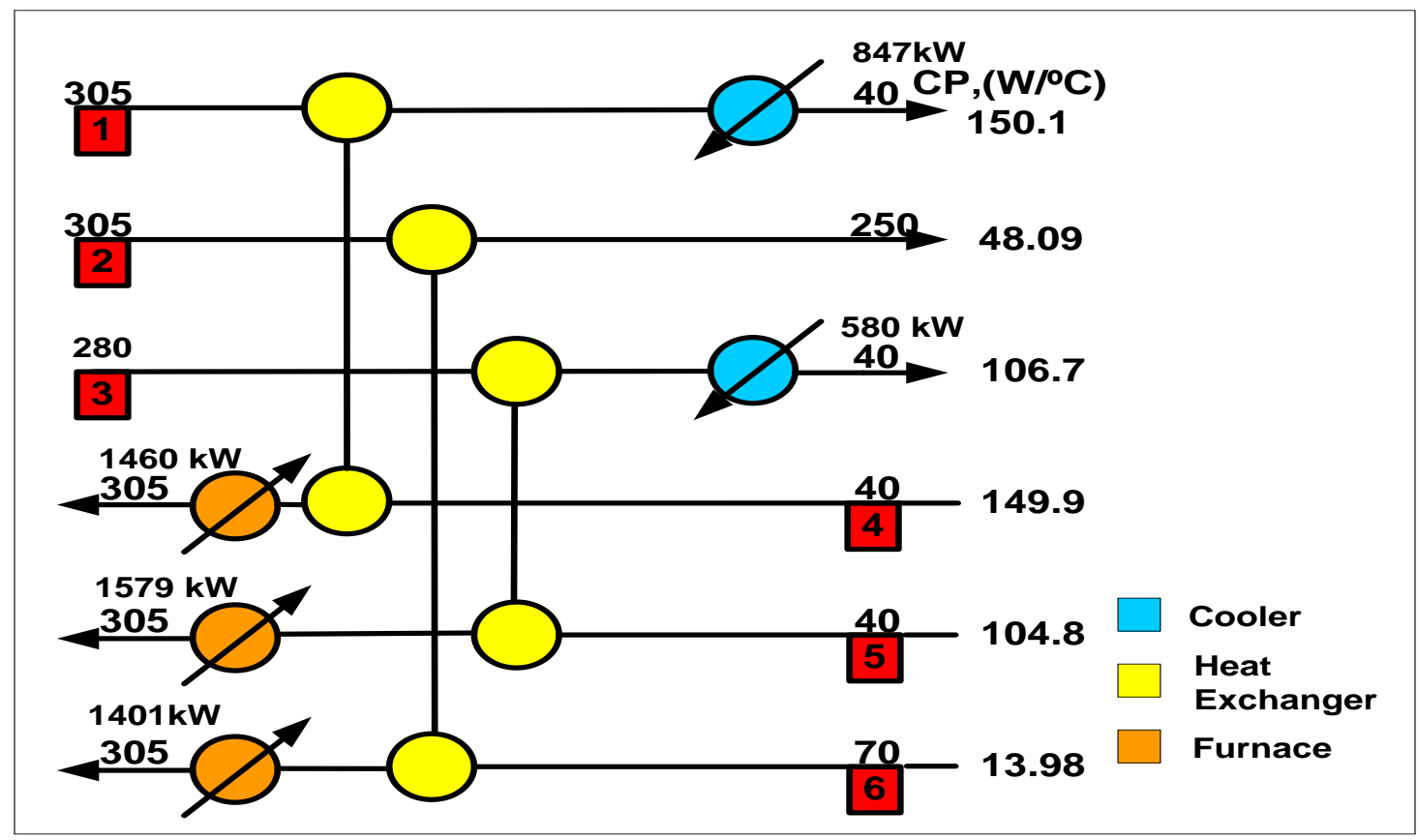

Figure 16: Proposed heat exchanger network for the new process proposed

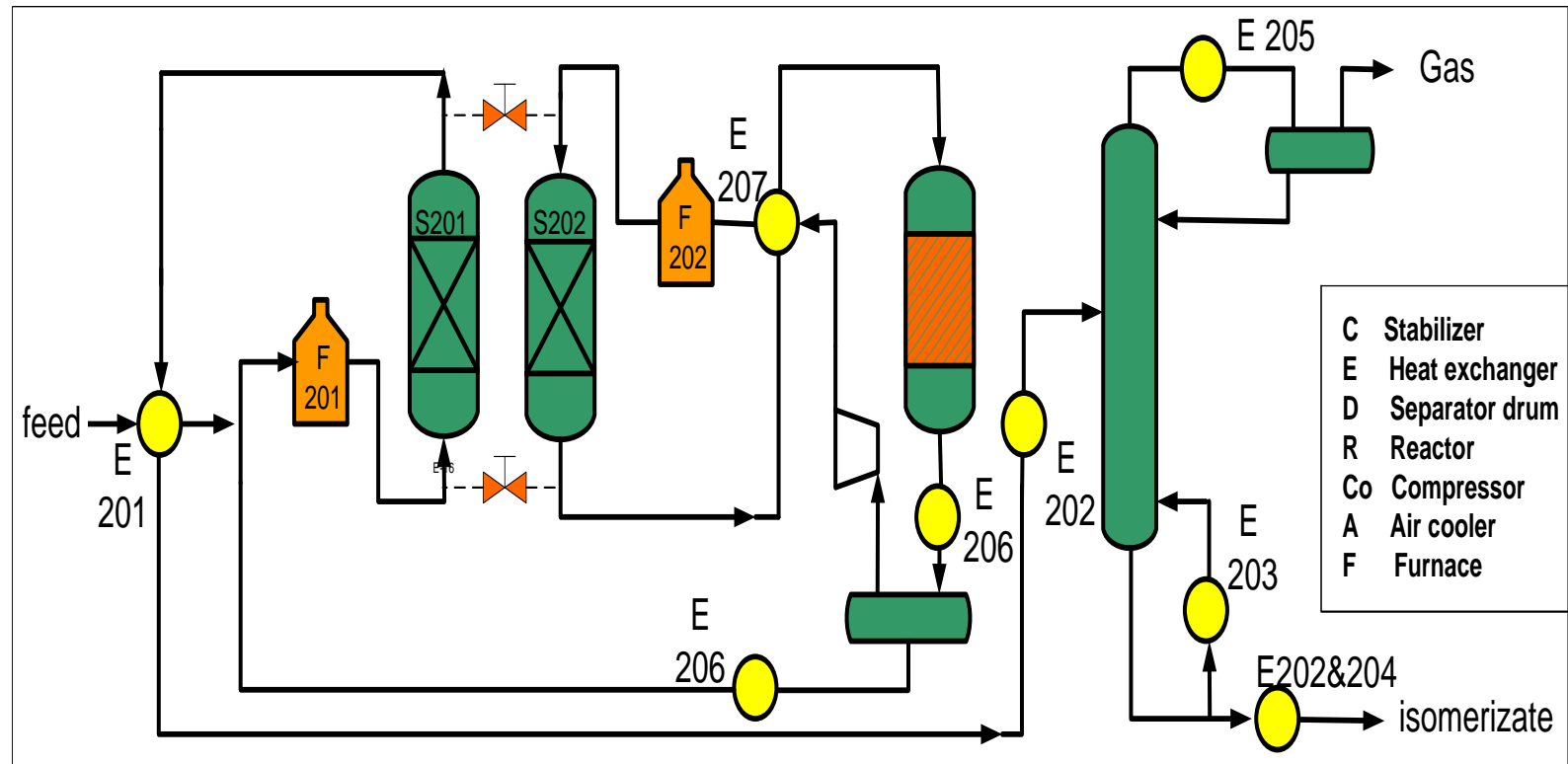

Figure 17: Modifying flow diagram of new isomerization process proposed 


\subsection{Optimization Problem Formulation for Isomerization Configurations}

According to the equations (42 - 44) utilizing the mathematical model presented previously and applying the optimal kinetic parameter obtained in the last study [1], and using the flow diagrams showed in the previous section, the optimization problem of all cases are stated as:

Given

Determine

So as to

Subjected to
Initial concentration, kinetic parameters, reactor configuration, process specifications

Initial concentration, kinetic parameters, reactor configuration, process specifications Maximise (RON \& yield), Minimise OAUC

Process constraints and linear bounds on all decision variables.

The optimization problem for each isomerization technology is written as: $\max$ $O B J$

$\mathrm{P}, \mathrm{T}, \mathrm{LHSV}, m_{r}$

s.t $\quad \mathrm{f}(\mathrm{x}(\mathrm{z}), \mathrm{u}(\mathrm{z}), \mathrm{v})=0$

$P^{L} \leq P \leq P^{U}$

$T^{L} \leq T \leq T^{U}$

$L H S V^{L} \leq L H S V \leq L H S V^{U}$

$m_{r}^{L} \leq m_{r} \leq m_{r}^{U}$ (model equation, equality constraint) (inequality constraints) (inequality constraints) (inequality constraints) (inequality constraints)

\subsection{Case Study 9: Energy Saving of the AJAM Proposed}

Table 17 presents the optimal results of optimization problem that shows positive effect of heat exchanger E207 added. Where, the temperature difference has reduced by minimizing the OAUC owning to minimize the heating and cooling amount required in comparison with the results without heat integration. Also, the RON has slightly been increased owing to increase the temperature and decreasing the LHSV. The cost saving owning to use the heat integration process is $2.905 \%$ compared without heat integration as a result to reduce the total heating required by $11.465 \%$ and total cooling required by $8.94 \%$. The new design achieved heat saving of $25.2 \%$ in comparison with the new configuration process of isomerization before making heat integration process. 
Table 17: Optimal performance, cost and operating conditions of optimization problem for the AJAM process

\begin{tabular}{lcccc}
\hline Variables & Symbol & Unit & \multicolumn{2}{c}{ Value } \\
\cline { 3 - 5 } & & & $\begin{array}{c}\text { With heat } \\
\text { integration }\end{array}$ & $\begin{array}{c}\text { Without } \\
\text { heat } \\
\text { integration }\end{array}$ \\
\hline OAUC & OAUC & $\$ / \mathrm{yr}$ & 14770103 & 15212319 \\
\hline Total heating required & $\mathrm{Q}_{\mathrm{H}}$ & $\mathrm{kW}$ & 4449.83 & 5027.4 \\
\hline Total cooling required & $\mathrm{Q}_{\mathrm{C}}$ & $\mathrm{kW}$ & 2736 & 3007 \\
\hline RON & $\mathrm{RON}$ & - & 90.93 & 90.81 \\
\hline Isomerizate Yield & $\mathrm{Yield}$ & $\%$ & 99.27 & 99.20 \\
\hline Initial temperature & $\mathrm{T}$ & $\mathrm{K}$ & 520.84 & 521.09 \\
\hline Reactor pressure & $\mathrm{P}$ & $\mathrm{MPa}$ & 2.11 & 2.104 \\
\hline LHSV & $\mathrm{LHSV}$ & $\mathrm{hr}^{-1}$ & 1.460 & 1.503 \\
\hline H$/$ HC mole ratio & $\mathrm{m}_{\mathrm{r}}$ & - & 3.37 & 3.46 \\
\hline Energy saving & $\mathrm{E}_{\mathrm{S}}$ & $\mathbf{\%}$ & & $\mathbf{2 5 . 2}$ \\
\hline
\end{tabular}

In order to assess the model parameters and providing sufficient evidence to ensure that values of model parameters evaluated do correspond to the global minimum of the objective function so that the developed process models is accurate, sensitivity analyses for $T, L H S V$, $P$ and $m_{r}$ values were performed. The information obtained from parametric sensitivity analysis is very useful for optimization and parameter estimation. It gives a clear indication which parameter has the largest impact on the accuracy of the model parameters. Sensitivity analysis is utilized for each of the estimated parameters by means of perturbations of the parameter value and is preferably in the range of $\pm 10 \%$, keeping the other parameters at their nominal values $[11,23]$. For each perturbation in the parameter values, the objective function is re-calculated and then for each parameter the perturbation percentage is plotted against the corresponding value of the objective function as shown in Figure 18 for each parameter. When all the perturbations in all the model parameters give the same minimum of the objective function with their original values ( $0 \%$ perturbation), that means the global minimum has been achieved. From Figure 18, it is clearly noticed that the calculated model parameters are the optimum since at $0 \%$ perturbation the perturbations of $T, L H S V, P$ and $m_{r}$ give the same minimum of the objective function with their original values. Therefore, it is demonstrated that the global minimum has been achieved. It is also seen from this Figure that $T$ and $L H S V$ have the biggest influence on the model parameters compared to $m_{r}$ and $P$. 


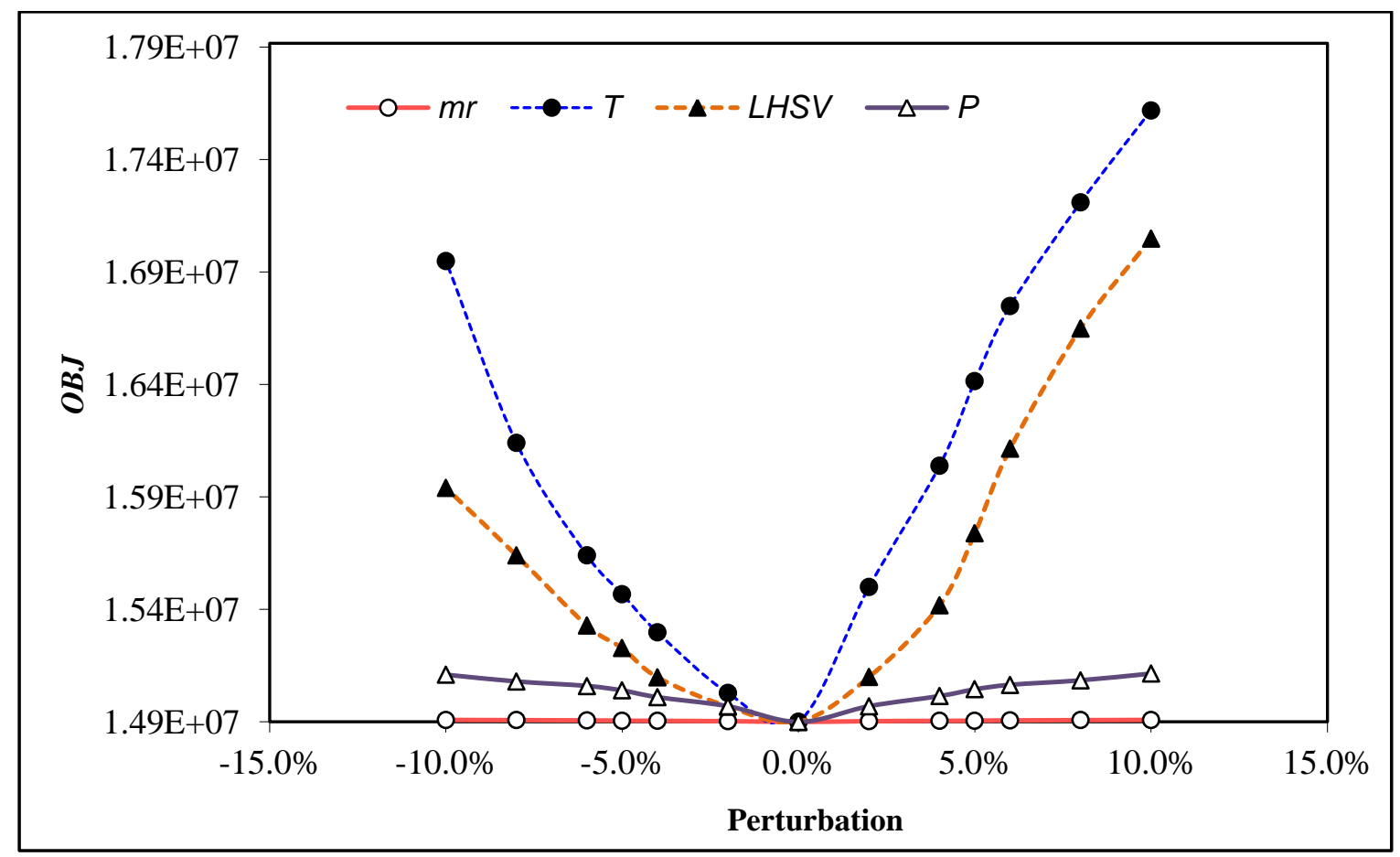

Figure 18: Sensitivity analysis of estimated model parameters for AJAM process

\section{Comparison of different Isomerization Configurations (Cost Saving, Yield and RON)}

The AJAM process gives the highest RON and yield with minimum cost. As presented in Table 18, a high cost saving verify by using the proposed configuration in a comparison with another configurations. The maximum cost saving is verified by $35 \%$ compared with Hexorb process, which had the maximum RON until this study. Also, beside the highest RON obtained by this study, this configuration gives the highest yield in comparison with all other technologies reported in such field.

Table 18: RON, yield and cost saving in AJAM process in comparison to different industrial isomerization processes

\begin{tabular}{lcccccc}
\hline Parameters & $\begin{array}{c}\text { AJAM } \\
\text { Process }\end{array}$ & Hexorb & TIP & Ipsorb & $\begin{array}{c}\text { DIH \& } \\
\text { DIP }\end{array}$ & DIH \\
& & & & & & \\
\hline Cost saving (\%) & - & 35.46 & 25.35 & 16.28 & 8.74 & 14.37 \\
\hline RON & $\mathbf{9 0 . 9 3}$ & 90.04 & 88.17 & 88.273 & 88.292 & 86.21 \\
\hline Yield (\%) & $\mathbf{9 9 . 2 7}$ & 96.89 & 97.06 & 97.27 & 97.51 & 96.827 \\
\hline
\end{tabular}




\section{Conclusions}

Several industrial isomerization technologies have been investigated in this study and optimized based on maximizing the RON and isomerizate yield, and minimizing of economic cost. It is found that the adding of DIP for each scheme has a positive effect on the RON, isomerizate and the operation cost. It is clearly observed that the recently proposed AJAM isomerization process gives the maximum RON, isomerizate yield and minimum economic cost in comparison to other molecular sieve technologies for the same feed stock and catalyst. The maximum cost saving (about 35\%), highest RON (90.93) is obtained by using the AJAM process in a comparison to another existing industrial configurations. Also, beside the highest RON and cost saving obtained, the AJAM process gives the highest yield $(99.27 \%)$ in comparison to all other processes. Also, energy saving opportunity of the AJAM process was investigated using a pinch technology giving more than $25 \%$ savings in energy.

\section{Nomenclature}

Symbol Description Unit

$A_{s} \quad$ cross section area of vapor flow rate $m^{2}$

$A_{t} \quad$ Total area of heat exchangers $m^{2}$

$A_{t 1} \quad$ Area of heat of E201 $m^{2}$

$A_{t 2} \quad$ Area of heat of E202 $\mathrm{m}^{2}$

$A_{t 3} \quad$ Area of heat of E203 $\mathrm{m}^{2}$

$A_{t 4} \quad$ Area of heat of E204 $\mathrm{m}^{2}$

$A_{t 5} \quad$ Area of heat of E205 $\mathrm{m}^{2}$

$A_{t 6} \quad$ Area of heat of E206 $\mathrm{m}^{2}$

$A_{t 7} \quad$ Area of heat of E207 $m^{2}$

AUCC Annual unit capital cost $\$ / y r$

AUOC Annual unit operating cost $\$ / y r$

bhp horsepower required in the compressor $H p$

$C_{A d} \quad$ Adsorber capital cost $\$$

$C_{c o}$ Compressor Cost $\quad \$$

$C_{\text {comp. }} \quad$ Compression cost $\$$ 


\begin{tabular}{|c|c|c|}
\hline$C_{\text {col. }}$ & Column Cost & $\$$ \\
\hline$C_{\text {cool }}$ & Cooling cost & $\$ / y r$ \\
\hline$C_{F}$ & Furnace cost & $\$ / y r$ \\
\hline$C_{H 2}$ & Hydrogen concentration & $\mathrm{mol} / \mathrm{m}^{3}$ \\
\hline$C_{H E}$ & Heat exchanger cost & $\$$ \\
\hline$C_{\text {Heat.. }}$ & Heating cost & $\$ / y r$ \\
\hline$C_{i}$ & Concentration of $i^{\text {th }}$ component & $\mathrm{mol} / \mathrm{m}^{3}$ \\
\hline$C_{i, i n}$ & Initial (inlet) concentration of ith component & $\mathrm{mol} / \mathrm{m}^{3}$ \\
\hline$C_{\text {pum }}$ & Pumping cost & $\$ / y r$ \\
\hline$C_{\text {pump }}$ & Pump cost & $\$$ \\
\hline$C_{r}$ & Reactor capital cost & $\$$ \\
\hline$C_{\text {sep. }}$ & Separator cost & $\$$ \\
\hline$C_{s t}$ & Stablization Cost & $\$$ \\
\hline$C_{\text {steam }}$ & Steam cost & $\$ / y r$ \\
\hline$C_{\text {tray }}$ & Tray Cost & $\$$ \\
\hline$C_{H 2}$ & Hydrogen cost & $\$ / y r$ \\
\hline$C p$ & The heat capacity of streams & $k J /\left(k g .{ }^{o} \mathrm{C}\right)$ \\
\hline$C p_{i, p}$ & Heat capacity of reaction product components & J/mol.K \\
\hline$C p_{i, r}$ & Heat capacity of reaction reactant components & $\mathrm{J} / \mathrm{mol} . \mathrm{K}$ \\
\hline$C p_{m}$ & Heat capacity of mixture & $J /(k g . k)$ \\
\hline$C p_{H 2}$ & The specific heat capacity at constant pressure & $J /(k g . k)$ \\
\hline$C p_{h 1, l}$ & heat capacity of hot stream as liquid in E201 & $k J /(k g k)$ \\
\hline$C p_{c l, l}$ & heat capacity of cold stream as liquid in E201 & $k J /(k g k)$ \\
\hline$C p_{h 1, v}$ & heat capacity of hot stream as vapor in E201 & $k J /(k g k)$ \\
\hline$C p_{c l, v}$ & $\begin{array}{l}\text { heat capacity of hot and cold stream respectively as } \\
\text { vapor in E201 }\end{array}$ & $k J /(k g k)$ \\
\hline$d_{t}$ & Tube diameter & $\mathrm{m}$ \\
\hline$D_{A d}$ & Adsorber diameter & $(m)$ \\
\hline$D_{c}$ & column diameter & $(\mathrm{m})$ \\
\hline$D_{r}$ & Reactor diameter & \\
\hline$F_{m}, F_{p}$ & Dimensionless factors that are function of the material & $(-)$ \\
\hline$F_{d}$ & construction, operating pressure and design, respectively & \\
\hline$G$ & raw material flow rate & $m^{3} / h r^{-1}$ \\
\hline$h_{v}$ & Vapor high & $m$ \\
\hline
\end{tabular}




\begin{tabular}{|c|c|c|}
\hline$h p$ & the isentropic compressor horsepower & $H p$ \\
\hline$i$ & hydrocarbon components number & $(-)$ \\
\hline$j$ & Reaction number & $(-)$ \\
\hline$l_{t}$ & Tray spacing & $m$ \\
\hline$L$ & Reactor bed length & $m$ \\
\hline$L_{A D}$ & Adsorber length & $m$ \\
\hline$L_{c}$ & Column (stabilizer) length & $m$ \\
\hline$L_{r}$ & Reactor length & $m$ \\
\hline$L_{s}$ & Separator length & $m$ \\
\hline$L H S V$ & Liquid hourly space velocity & $h r^{-1}$ \\
\hline$m_{r}$ & Mole ratio of hydrogen to light naphtha & $(-)$ \\
\hline$N_{t}$ & Number of tray & $(-)$ \\
\hline$P$ & Reactor pressure & $P a$ \\
\hline Pin, $\mathrm{P}_{\text {out }}$ & Inlet and outlet pressure in the compressor & $P a$ \\
\hline$P_{n s}$ & Naphtha stream pressure & $P a$ \\
\hline$q_{F}$ & Furnace heat duty & $k J / r h$ \\
\hline$q_{E 201}$ & rate of heat transfer through E201 & $k J / r h$ \\
\hline$q_{E 202}$ & rate of heat transfer through E202 & $k J / r h$ \\
\hline$q_{E 203}$ & rate of heat transfer through E203 & $k J / r h$ \\
\hline$q_{E 204}$ & rate of heat transfer through E204 & $k J / r h$ \\
\hline$q_{E 205}$ & rate of heat transfer through E205 & $k J / r h$ \\
\hline$q_{E 206}$ & rate of heat transfer through E206 & $k J / r h$ \\
\hline$q_{E 207}$ & rate of heat transfer through E207 & $k J / r h$ \\
\hline$q_{p}$ & power of the pump & $k J / h r$ \\
\hline$Q_{\text {in }}$ & Flow rate of hydrogen at compressor section & $m^{3} / h r$ \\
\hline$Q_{l n}$ & Liquid Flow rate of light naphtha & $m^{3} / h r$ \\
\hline$Q_{v}$ & Hydrogen volumetric flow rate & $m^{3} / h r$ \\
\hline$R O N$ & Research octane number & $(-)$ \\
\hline$T 1_{b, c}$ & Boiling temperature of cold and stream in E201 & $K$ \\
\hline$T 1_{b, h}$ & Boiling temperature of hot stream in E201 & $K$ \\
\hline$T 1_{i, h}$ & The inlet temperature of hot stream into E201 & $K$ \\
\hline$T 1_{i, c}$ & The inlet temperature of cold stream into E201 & $K$ \\
\hline$T 1_{o, h}$ & The outlet temperature of hot stream from the E201 & $K$ \\
\hline$T 1_{o, c}$ & The outlet temperature of cold from E201 & $K$ \\
\hline
\end{tabular}




\begin{tabular}{|c|c|c|}
\hline$T_{o, F}, T_{i, F}$ & Outlet and inlet furnace temperature & $K$ \\
\hline$u_{a}$ & settling velocity & $m / s$ \\
\hline$u_{v}$ & Vapor velocity & $m / s$ \\
\hline$U_{1}$ & Heat transfer coefficient of E201 & $k J /\left(m^{2} . K . h r\right)$ \\
\hline$U_{2}$ & Heat transfer coefficient of E202 & $k J /\left(m^{2} . K . h r\right)$ \\
\hline$U_{3}$ & Heat transfer coefficient of E203 & $k J /\left(m^{2} . K . h r\right)$ \\
\hline$U_{4}$ & Heat transfer coefficient of E204 & $k J /\left(m^{2} . K . h r\right)$ \\
\hline$U_{5}$ & Heat transfer coefficient of E205 & $k J /\left(m^{2} . K . h r\right)$ \\
\hline$U_{6}$ & Heat transfer coefficient of E206 & $k J /\left(m^{2} . K . h r\right)$ \\
\hline$U_{7}$ & Heat transfer coefficient of E207 & $k J /\left(m^{2} . K . h r\right)$ \\
\hline$V_{A d}$ & Adsorber bed volume & $m^{3}$ \\
\hline$V_{w}$ & Maximum vapor rate & $k g / \mathrm{s}$ \\
\hline$W_{5 A}$ & Weight of 5A zeolite catalyst & $k g$ \\
\hline$W_{\text {cat }}$ & Weight of 5A zeolite catalyst & $k g$ \\
\hline$W_{H 2}$ & Weight flow rate of hydrogen inter to reactor & $k g / h r$ \\
\hline$W_{H 2, \mathrm{C}}$ & weight rate of hydrogen consumption & $k g / h r$ \\
\hline$W_{H 2, i n}$ & weight rate of hydrogen inlet to the reactor & $k g / h r$ \\
\hline$W_{H 2, o}$ & weight rate of hydrogen out from the reactor & $k g / h r$ \\
\hline$W_{H 2 O}$ & Weight flow rate of cooling water & $k g / h r$ \\
\hline$W_{l n}$ & Weight flow rate of light naphtha & $k g / h r$ \\
\hline$W_{\text {steam }}$ & Weight flow rate of steam & $k g / h r$ \\
\hline$X$ & Inert bed high & $m$ \\
\hline$y$ & Mole fraction & $(-)$ \\
\hline$Z$ & Compressibility factor & $(-)$ \\
\hline
\end{tabular}

\section{References}

[1] Ahmed, M.A., Jarullah, A.T., Abed, F.M., Mujtaba, I.M., 2018. Modelling of an Industrial Naphtha Isomerization Reactor and Development and Assessment of a New Isomerization Process. Chemical Engineering Research and Design. 137, 33-46.

[2] Yasakova, E.A., Sitdikova, A.V., 2010. Tendency of Isomerization Process Development in Russia and Foreign Countries. Oil and Gas Business. 1, 1-7.

[3] Anderson, G., Rosin, R., Stine, M., Hunter, M., 2004. New solutions for light paraffin isomerization. NPRA Annual Meeting, Washington DC, AM, 04-46. 
[4] Graeme, S., Ross, J., Nobel, A., Axens, N., 2004. Advanced solutions for paraffins isomerization. Proceedings of the National Petrochemical and Refiners Association Annual Meeting, 21-23.

[5] Domergue, B., Watripont, L., 2005. Paraffins isomerization options. Petroleum technology quarterly. 10, 21-25.

[6] Barcia, P.S., Silva, J.A., Rodrigues, A.R.E., 2010. Adsorption dynamics of C5/C6 isomerate fractions in zeolite beta for the octane improvement of gasoline. Energy \& Fuels. 24, 1931-1940.

[7] T.C. Holcombe, 1980. Total isomerization process, US 4210771 A.

[8] Koncsag, C.I., Tutun, I.A., Safta, C., 2011. Study of C5/C6 isomerization on Pt/H-zeolite catalyst in industrial conditions. Ovidius Univ. Annal. Chem., 22, 102-106.

[9] Gary, J.H., Handwerk, G.E., Kaiser, M.J., 2007. Petroleum refining: technology and economics, New York, CRC press.

[10] Douglas, J.M., 1988. Conceptual Design Chemical Processes, McGraw-Hill, New York,

[11] Jarullah, A.T., 2011. Kinetic Modelling Simulation and Optimal Operation of Trickle Bed Reactor for Hydrotreating of Crude Oil, Kinetic Parameters Estimation of Hydrotreating Reactions in Trickle Bed Reactor (TBR) via Pilot Plant Experiments; Optimal Design and Operation of an Industrial TBR with Heat Integration and Economic Evaluation, Ph.D. Thesis, University of Bradford, UK.

[12] Towler, G., Sinnott, R.K., 2013. Chemical engineering design: principles, practice and economics of plant and process design, $2^{\text {nd }}$ ed., Elsevier, UK.

[13] Smith, R., 2005. Chemical process: design and integration, John Wiley \& Sons, Chichester, UK.

[14] Rosales-Quitero, A., Vargas-Villamil F., 2009. On the multiplicities of a catalytic distillation column for the deep hydrodesulfurization of light gas oil. Industrial \& Engineering Chemistry Research. 48, 1259-1269.

[15] Sinnott, R., 1999. Coulson \& Richardson's Chemical Engineering: Volume 6/Chemical Engineering Design, Elsevier Butterworth Heinemann, UK.

[16] Bouton, G.R., Luyben, W.L., 2008. Optimum economic design and control of a gas permeation membrane coupled with the hydrodealkylation (HDA) process. Industrial \& Engineering Chemistry Research. 47, 1221-1237. 
[17] Mohammed, A.E., Jarullah, A.T., Gheni, S.A., Mujtaba, I.M., 2016. Optimal design and operation of an industrial three phase reactor for the oxidation of phenol. Computers \& Chemical Engineering. 94, 257-271.

[18] Weinert, J.X., Shaojun, L., Ogden, J.M., Jianxin, M., 2007. Hydrogen refueling station costs in Shanghai. International Journal of Hydrogen Energy. 32, 4089-4100.

[19] Alibaba. 2017. Zeolite price. www.alibaba.com. [accessed 12 February].

[20] Frédéric, B., Cordin, A., Stefan, S.B., Jürg, S., 2017. Theoretical analysis of steam generation methods-Energy, $\mathrm{CO}_{2}$ emission, and cost analysis. Energy. 129, 114-121.

[21] Linnhoff, B., Hindmarsh, E., 1983. The pinch design method for heat exchanger networks. Chemical Engineering Science. 38, 745-763.

[22] Gundepsen, T., Naess, L., 1988. The synthesis of cost optimal heat exchanger networks: an industrial review of the state of the art. Computers \& chemical engineering. 12, 503-530.

[23] Jarullah, A. T., 2018. Modelling and Simulation of a Fluidized Bed Reactor for Minimum Ammonium Nitrate and Reduction of NOx. Emissions. Chemical Engineering Research Bulletin. 20, 8-18. 


\section{Appendix A}

Table A1: Mathematical modelling equations

Mass balance equation:

$G \frac{d C i}{d V}=\sum_{j=1}^{m} a_{j} \cdot r_{j}$

Energy balance equation:

$G \frac{d T}{d V}=\frac{1}{\rho C_{p}^{m}} \sum_{j=1}^{m} Q_{j} \cdot a_{j} \cdot r_{j}$

$\cap_{D}=\frac{1.06036}{\left(T^{*}\right)^{0.1561}}+\frac{0.193}{\exp \left(0.47635 T^{*}\right)}$

$+\frac{1.03587}{\exp \left(0.01529 T^{*}\right)}$

$+\frac{1.76474}{\exp \left(3.89411 T^{*}\right)}$

$T^{*}=\frac{T}{\varepsilon_{i k} / C_{B}}$

$T_{c, i k}=\sqrt{T_{c i} T_{c k}}$

$\varepsilon_{i k} / C_{B}=0.75 T_{c, i k}$

$k_{j}=A_{j} \exp \left(\frac{-E_{j}}{R T}\right)$

$C_{i}=\left(y_{i} p\right) /\left(Z_{i} R T\right)$

Effectiveness factor

$\eta_{j}=\frac{\tanh \varphi_{\mathrm{j}}}{\varphi_{\mathrm{j}}}$

$\varphi=\frac{V_{P}}{S_{P}} \sqrt{\left(\frac{n+1}{2}\right)\left(\frac{r_{j} C_{i}^{-1} \rho_{p}}{D_{e, i}}\right)}$

Effective diffusivity:

$D_{e, i}=\frac{\epsilon_{S}}{\mathrm{U}} \frac{1}{\frac{1}{D_{m i}^{g}}+\frac{1}{D_{k i}}}$

$\mathrm{T}=\frac{1-0.5 \log \varepsilon_{s}}{\epsilon_{s}}$

$D_{k i}=349200 r_{g} \sqrt{\frac{T}{M W_{i}}}$

$D_{m i}^{g}=(1-y i) 1 / \sum_{k \neq i}^{N C G} \frac{y_{k}}{D_{i, k}}$

$D_{i, k}=188.2458 * 10^{-20} \sqrt{T^{3}\left(\frac{1}{M W_{i}}+\frac{1}{M W_{k}}\right)}$

Equations of RON estimation:

$R O N=\sum_{i=1}^{m}\left(R_{O N} \cdot y_{i}\right)+\beta$

$\beta=\frac{1}{100} \sum_{i=1}^{m-1} \sum_{j=2}^{m} \beta_{i} \beta_{j} y_{i} y_{j}$

$\beta_{i}=\alpha\left(\frac{D i_{i}}{D i_{\max }}\right)^{\gamma}$

Yield calculation equation:

Yield $=M_{\text {iso }} / M_{l n}$

$$
\begin{gathered}
* \frac{1}{P \sigma_{i, k}^{2} \cap_{D}} \\
\sigma_{i, k}=\frac{\sigma_{i}+\sigma_{k}}{2} \\
\sigma_{i}=1.18 * 10^{-9}\left(V_{b i}\right)^{\frac{1}{3}}
\end{gathered}
$$

